\title{
Reinforcing Low-Volume Fraction Nano-TiN Particulates to Monolithical, Pure Mg for Enhanced Tensile and Compressive Response
}

\author{
Ganesh Kumar Meenashisundaram ${ }^{1}$, Mui Hoon Nai ${ }^{1}$, Abdulhakim Almajid ${ }^{2}$ and \\ Manoj Gupta ${ }^{1, *}$ \\ 1 Department of Mechanical Engineering, National University of Singapore, 9 Engineering Drive 1, \\ Singapore 117576, Singapore; ganesh_kumar@u.nus.edu (G.K.M.); mbinmhb@nus.edu.sg (M.H.N.) \\ 2 Mechanical Engineering Department, College of Engineering, King Saud University, PO Box 800, \\ Riyadh 11421, Saudi Arabia; aalmajid@ksu.edu.sa \\ * Correspondence: mpegm@nus.edu.sg; Tel.: +65-6516-6358
}

Academic Editor: Daolun Chen

Received: 26 December 2015; Accepted: 23 February 2016; Published: 26 February 2016

\begin{abstract}
Novel $\mathrm{Mg}(0.58,0.97,1.98$ and 2.5) vol. \% TiN nanocomposites containing titanium nitride (TiN) nanoparticulates of $\sim 20 \mathrm{~nm}$ size are successfully synthesized by a disintegrated melt deposition technique followed by hot extrusion. Microstructural characterization of Mg-TiN nanocomposites indicate significant grain refinement with $\mathrm{Mg} 2.5$ vol. \% TiN exhibiting a minimum grain size of $\sim 11 \mu \mathrm{m}$. X-ray diffraction studies of Mg-TiN nanocomposites indicate that addition of up to 1.98 vol. \% TiN nanoparticulates aids in modifying the strong basal texture of pure Mg. An attempt is made to study the effects of the type of titanium (metal or ceramic), size, and volume fraction addition of nanoparticulates on the microstructural and mechanical properties of pure magnesium. Among the major strengthening mechanisms contributing to the strength of Mg-Ti-based nanocomposites, Hall-Petch strengthening was found to play a vital role. The synthesized Mg-TiN nanocomposites exhibited superior tensile and compression properties indicating significant improvement in the fracture strain values of pure magnesium under loading. Under tensile and compression loading the presence of titanium (metal or ductile phase) nanoparticulates were found to contribute more towards the strengthening, whereas ceramics of titanium (brittle phases) contribute more towards the ductility of pure magnesium.
\end{abstract}

Keywords: $\operatorname{Mg}(0.58,0.97,1.98,2.5)$ vol. \% TiN; nanocomposites; grain refinement; X-ray diffraction; tensile; compression; Hall-Petch mechanism; titanium (metal or ceramic); nanoparticulates

\section{Introduction}

For several years, research and development on lightweight materials has been of particular interest owing to the significant emphasis on greenhouse gas reduction and improving fuel efficiency, especially in the transportation sector. For every $10 \%$ of total vehicle weight reduction, vehicle fuel economy has been estimated to be improved by 7\% [1]. Magnesium $(\mathrm{Mg})$, with high specific mechanical properties, is a potential candidate material for realizing lightweight construction. With a density of $1.74 \mathrm{~g} / \mathrm{cm}^{3}, \mathrm{Mg}$ is the lightest of all the structural metals and has other important properties, such as good castability, high thermal stability, good damping characteristics, and resistance to electromagnetic radiation [2-4]. Further, $\mathrm{Mg}$ materials have also recently become of great interest for biomedical applications. Low strength, insufficient ductility, and high thermal coefficient of expansion are some of the deficits of $\mathrm{Mg}$ materials, which restricts their extensive applications. Simultaneous 
improvements in the strength and ductility of magnesium materials can be effectively realized by dispersion strengthening for which selection of suitable reinforcements is of prime importance.

Reinforcements can be classified based on their type such as: (a) metallic and (b) ceramic, and size such as (a) micron $\left(1 \times 10^{-6}\right.$ to $\left.1 \times 10^{-4}\right)$, (b) submicron $\left(1 \times 10^{-7}\right.$ to $\left.1 \times 10^{-6}\right)$, and (c) nano $\left(1 \times 10^{-9}\right.$ to $\left.1 \times 10^{-7}\right)$. Among the reinforcement types, more attention on altering the properties of magnesium by addition of inexpensive nanoparticulates (NPs) is highly noticeable. Titanium (Ti) has excellent corrosion resistance and high specific strength. Due to their high cost, Ti and Ti alloys are mostly used in the aerospace industry, racing cars, and special purpose parts for the automobile industry [5]. Further, Ti and Ti alloys are considered as the most attractive metallic materials for biomedical applications targeting permanent implants [6]. They are used for load bearing applications, especially in orthopedics [6].

Ceramics of Ti include titanium carbide ( $\mathrm{TiC})$, titanium nitride $(\mathrm{TiN})$, titanium dioxide $\left(\mathrm{TiO}_{2}\right)$, and titanium diboride $\left(\mathrm{TiB}_{2}\right)$. Among the ceramics of $\mathrm{Ti}, \mathrm{TiC}, \mathrm{TiB}_{2}$, and $\mathrm{TiN}$ have exceptional hardness, modulus, and have high resistance to erosion and corrosion properties. They are used as coatings for improving the wear resistance of implants. Even though the mechanical properties of $\mathrm{TiO}_{2}$ is comparatively lower than the other ceramics of Ti, low cost, non-toxic, chemical and biological stability properties make $\mathrm{TiO}_{2}$ an attractive reinforcement for metal matrix composites [7]. Further, $\mathrm{TiO}_{2}$ is a bioactive material and a preferred reinforcement to improve the bioactivity of composites targeting biomedical applications [8]. Previously, the authors have studied the effects of low-volume fraction $\mathrm{Ti}$ [9] and ceramics of $\mathrm{Ti}\left(\mathrm{TiB}_{2}\right.$ [10], $\mathrm{TiC}$ [11], and $\mathrm{TiO}_{2}$ [12]) on the microstructural and mechanical properties of pure $\mathrm{Mg}$ synthesized by utilizing a disintegrated melt deposition technique followed by hot extrusion. The results of the literature search, however, reveal that no attempt is made to date to study the effects of TiN NPs to alter the tensile and compressive response of monolithic, pure $\mathrm{Mg}$ in the absence of microstructural factors related to the presence of precipitates and heat treatment.

Accordingly, in the present study, $\mathrm{Mg}$ matrix reinforced with low volume fraction $(0.58,0.97$, 1.98, and 2.5) vol. \% TiN NPs are synthesized by a disintegrated melt deposition technique followed by hot extrusion. The hot extruded Mg-TiN nanocomposite samples were then characterized for physical, microstructural, and mechanical properties and compared to that of previously-synthesized low-volume fraction $\mathrm{Ti}$ (metallic) and ceramics of $\mathrm{Ti}\left(\mathrm{TiB}_{2}, \mathrm{TiC}\right.$ and $\left.\mathrm{TiO}_{2}\right)$ reinforced $\mathrm{Mg}$ nanocomposites. Particular emphasis of this study is to analyze the effects of type of reinforcements (metallic and ceramic Ti NPs) on the microstructural and mechanical properties of pure Mg.

\section{Results}

\subsection{Density and Porosity Measurements}

The results of density measurements of the synthesized pure $\mathrm{Mg}$ and $\mathrm{Mg}$-TiN nanocomposites are shown in Table 1. The reference density of the Mg-TiN nanocomposites are theoretically calculated using the rule of mixtures. With the addition of up to 2.5 vol. \% TiN NPs, a marginal increase in the experimental density value of pure $\mathrm{Mg}$ was observed and $\mathrm{Mg} 2.5$ vol. \% TiN nanocomposite exhibited a maximum of $\sim 1.8225 \mathrm{~g} / \mathrm{cm}^{3}$, which is only $\sim 5 \%$ greater than that of pure $\mathrm{Mg}$. Further, the porosity value of the synthesized Mg materials was found to increase with the addition of TiN NPs and $\mathrm{Mg} 2.5$ vol. \% TiN nanocomposite exhibited a maximum porosity of $\sim 0.5 \%$.

\subsection{X-ray Diffraction Studies}

Figure 1 shows the X-Ray diffractogram of TiN and hot extruded pure $\mathrm{Mg}, \mathrm{Mg}$-TiN nanocomposites taken along transverse and longitudinal sections of the samples. The high intensity $\mathrm{Mg}$ peaks were prominently seen and the peaks corresponding to TiN were not visible in the synthesized $\mathrm{Mg}$-TiN nanocomposites which is due to the limitation of filtered X-rays to detect secondary phases with a low-volume fraction [13]. However, the presence of TiN NPs in the Mg-TiN nanocomposites can be confirmed through microstructural characterization and changes in the intensity of $\mathrm{Mg}$ peaks 
observed through X-ray diffraction studies. In the X-ray diffractogram of as-extruded pure $\mathrm{Mg}$, the peaks observed at $2 \theta=32^{\circ}, 34^{\circ}$, and $36^{\circ}$ correspond to prismatic (10-10), basal (0002), and pyramidal (10-11) planes, respectively. With the addition of TiN NPs, changes in the intensity of basal plane of pure $\mathrm{Mg}$ were observed. The ratio of XRD intensities of $\mathrm{Mg}$ (such as pyramidal, basal, and prismatic) to the maximum XRD intensity ( $\mathrm{I} / \mathrm{I}_{\max }$ ) observed for the synthesized pure $\mathrm{Mg}$ and $\mathrm{Mg}$-TiN nanocomposites is given in Table 2.

Table 1. Density and coefficient of thermal expansion (CTE) measurements of pure magnesium and synthesized Mg-TiN nanocomposites.

\begin{tabular}{|c|c|c|c|c|c|c|c|}
\hline \multirow[b]{2}{*}{ S1. No } & \multirow[b]{2}{*}{ Material } & \multicolumn{2}{|c|}{ Reinforcement } & \multicolumn{3}{|c|}{ Density Measurements } & \multirow[b]{2}{*}{$\begin{array}{c}\text { CTE } \\
\left(\times 10^{-6} / \mathrm{K}\right)\end{array}$} \\
\hline & & $(\mathrm{Wt} \%)$ & (Vol \%) & $\begin{array}{c}\text { Theoretical } \\
\text { Density } \\
\left(\mathrm{g} / \mathrm{cm}^{3}\right)\end{array}$ & $\begin{array}{l}\text { Experimental } \\
\text { Density } \\
\left(\mathrm{g} / \mathrm{cm}^{3}\right)\end{array}$ & $\begin{array}{l}\text { Porosity } \\
(\%)\end{array}$ & \\
\hline 1 & $\mathrm{Mg}$ & Nil & Nil & 1.7400 & 1.7356 & 0.2530 & 27.00 \\
\hline 2 & $\mathrm{Mg} 0.58 \mathrm{TiN}$ & 1.78 & 0.58 & 1.7612 & 1.7589 & 0.1322 & 25.54 \\
\hline 3 & $\mathrm{Mg} 0.97 \mathrm{TiN}$ & 2.95 & 0.97 & 1.7750 & 1.7695 & 0.3382 & 24.63 \\
\hline 4 & $\mathrm{Mg} 1.98 \mathrm{TiN}$ & 5.9 & 1.98 & 1.8125 & 1.8050 & 0.4123 & 24.58 \\
\hline 5 & $\mathrm{Mg} 2.5 \mathrm{TiN}$ & 7.37 & 2.5 & 1.8315 & 1.8225 & 0.4917 & 22.61 \\
\hline
\end{tabular}

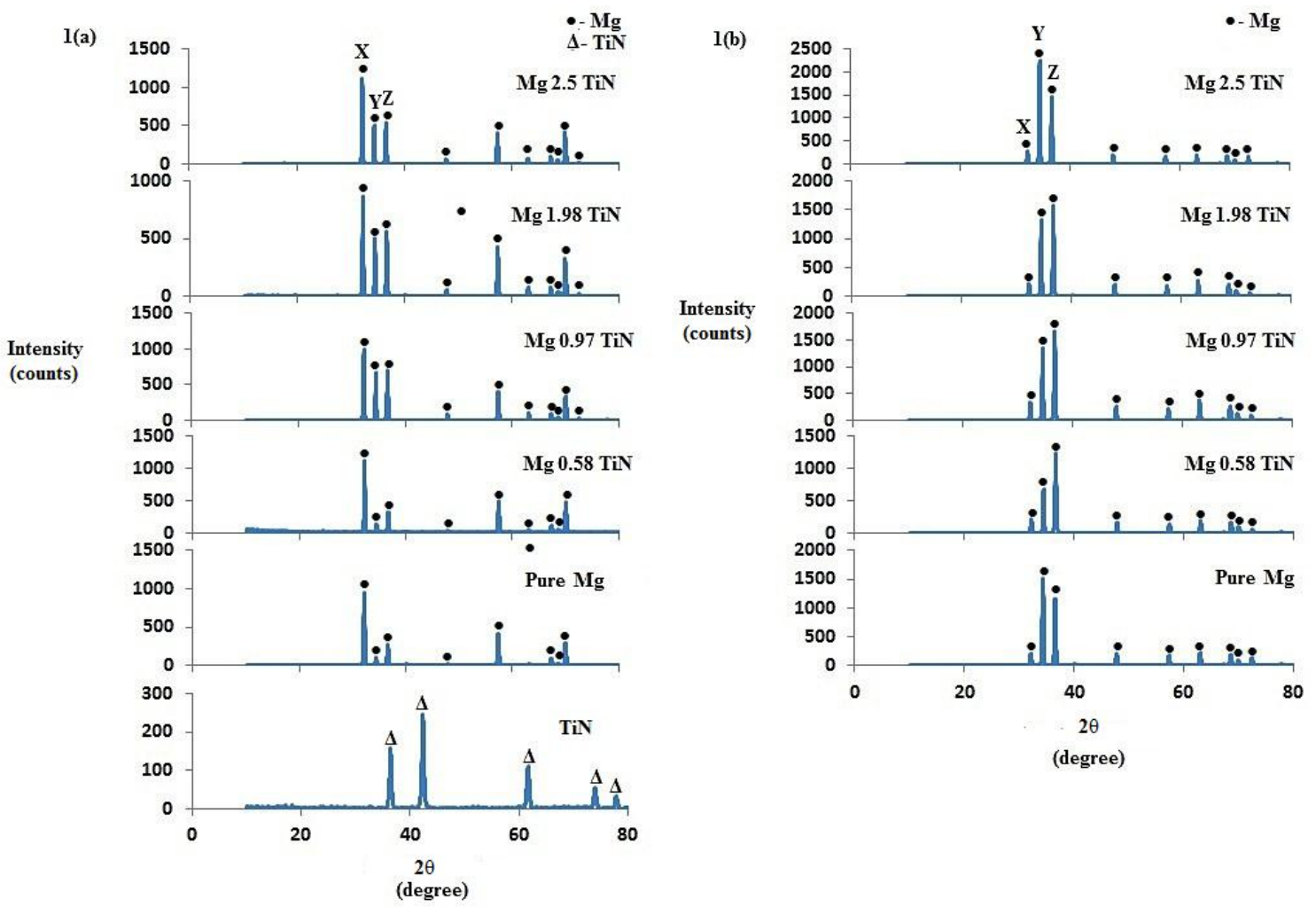

Figure 1. X-ray diffractograms of TiN nanopowder, pure $\mathrm{Mg}$, and $\mathrm{Mg}$ - TiN nanocomposites taken along: (a) transverse direction and (b) longitudinal direction of hot extruded samples. $\mathrm{X}, \mathrm{Y}$, and $\mathrm{Z}$ represent $2 \theta=32^{\circ}, 34^{\circ}$, and $36^{\circ}$ corresponding to (10-10) prism, (0002) basal, and (10-11) pyramidal planes, respectively. 
Table 2. X-ray diffractogram results of as-extruded Mg-TiN nanocomposites.

\begin{tabular}{|c|c|c|c|}
\hline Material & Section & Plane & $\mathrm{I} / \mathrm{I}_{\max }$ \\
\hline \multirow{6}{*}{ Pure Mg } & \multirow{3}{*}{$\mathrm{T}$} & 10-10 Prism & 1.000 \\
\hline & & 0002 Basal & 0.104 \\
\hline & & 10-11 Pyramidal & 0.278 \\
\hline & \multirow{3}{*}{$\mathrm{L}$} & 10-10 Prism & 0.136 \\
\hline & & 0002 Basal & 1.000 \\
\hline & & 10-11 Pyramidal & 0.764 \\
\hline \multirow{6}{*}{$\mathrm{Mg} 0.58 \mathrm{TiN}$} & \multirow{3}{*}{$\mathrm{T}$} & 10-10 Prism & 1.000 \\
\hline & & 0002 Basal & 0.131 \\
\hline & & 10-11 Pyramidal & 0.295 \\
\hline & \multirow{3}{*}{$\mathrm{L}$} & 10-10 Prism & 0.166 \\
\hline & & 0002 Basal & 0.551 \\
\hline & & 10-11 Pyramidal & 1.000 \\
\hline \multirow{6}{*}{$\mathrm{Mg} 0.97 \mathrm{TiN}$} & \multirow{3}{*}{$\mathrm{T}$} & 10-10 Prism & 1.000 \\
\hline & & 0002 Basal & 0.674 \\
\hline & & 10-11 Pyramidal & 0.685 \\
\hline & \multirow{3}{*}{$\mathrm{L}$} & 10-10 Prism & 0.195 \\
\hline & & 0002 Basal & 0.813 \\
\hline & & 10-11 Pyramidal & 1.000 \\
\hline \multirow{6}{*}{$\mathrm{Mg} 1.98 \mathrm{TiN}$} & \multirow{3}{*}{$\mathrm{T}$} & 10-10 Prism & 1.000 \\
\hline & & 0002 Basal & 0.596 \\
\hline & & 10-11 Pyramidal & 0.661 \\
\hline & \multirow{3}{*}{$\mathrm{L}$} & 10-10 Prism & 0.147 \\
\hline & & 0002 Basal & 0.842 \\
\hline & & 10-11 Pyramidal & 1.000 \\
\hline \multirow{6}{*}{$\mathrm{Mg} 2.5 \mathrm{TiN}$} & \multirow{3}{*}{$\mathrm{T}$} & 10-10 Prism & 1.000 \\
\hline & & 0002 Basal & 0.460 \\
\hline & & 10-11 Pyramidal & 0.464 \\
\hline & \multirow{3}{*}{$\mathrm{L}$} & 10-10 Prism & 0.130 \\
\hline & & 0002 Basal & 1.000 \\
\hline & & 10-11 Pyramidal & 0.651 \\
\hline
\end{tabular}

Notes: $\mathrm{T}$ and $\mathrm{L}$ represents XRD taken along transverse and longitudinal sections of Mg-TiN samples; I is the XRD intensity from prismatic, basal, and pyramidal plane of pure $\mathrm{Mg} ; \mathrm{I}_{\max }$ is the maximum XRD intensity from either prism, basal, and pyramidal plane.

Along the transverse direction (perpendicular to the extrusion direction), the intensity corresponding to the basal plane of pure $\mathrm{Mg}$ was found to increase with up to $0.97 \mathrm{vol} . \% \mathrm{TiN}$ NPs addition and $\mathrm{Mg} 0.97 \mathrm{TiN}$ exhibited a maximum $\mathrm{I}_{\text {basal }} / \mathrm{I}_{\max }$ value of $\sim 0.674$. With further addition of TiN NPs, the intensity corresponding to the basal plane of pure Mg was found to decrease and among the synthesized Mg-TiN nanocomposites, $\mathrm{Mg} 2.5$ vol. \% TiN exhibited a minimum $\mathrm{I}_{\text {basal }} / \mathrm{I}_{\max }$ of $\sim 0.460$. Further, the intensity corresponding to the prismatic plane $\left(2 \theta=32^{\circ}\right)$ was found to be the maximum for all the synthesized Mg materials. Along the longitudinal direction (parallel to the extrusion direction), pure Mg exhibited strong basal texture with maximum XRD intensity corresponding to the basal plane $\left(2 \theta=34^{\circ}\right)$. With the addition of up to $1.98 \mathrm{vol}$. \% TiN NPs, the intensity corresponding to the basal plane of pure Mg was found to decrease. With further addition of TiN NPs (2.5 vol. \%), the dominance of basal plane intensity or basal texture was still observed.

\subsection{Microstructural Characterization}

The results of grain size measurements conducted on optical micrographs of synthesized pure $\mathrm{Mg}$ and Mg-TiN nanocomposites (Figure 2) are shown in Table 3. It is observed that the grain size of pure $\mathrm{Mg}$ decreases with the addition of TiN NPs and a minimum of $\sim 11 \mu \mathrm{m}$, which is $\sim 57 \%$ lower than 
that of pure $\mathrm{Mg}$, was observed with $\mathrm{Mg} 2.5$ vol. \% TiN nanocomposite. Further, from the micrographs (Figure 3) representing the distribution of TiN NPs within the synthesized Mg-TiN nanocomposites, minimal agglomeration of TiN particulates was observed.

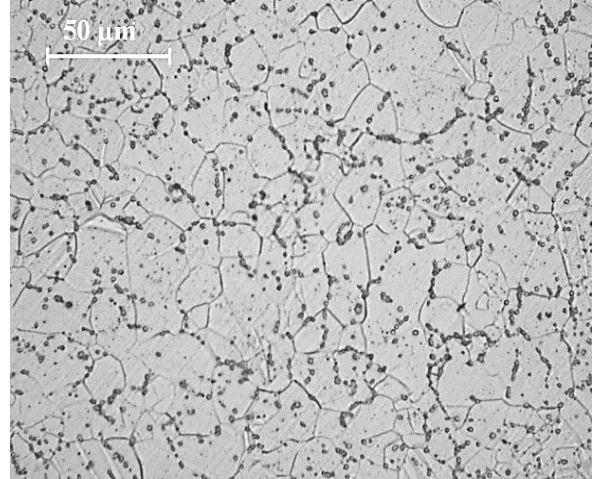

(a)

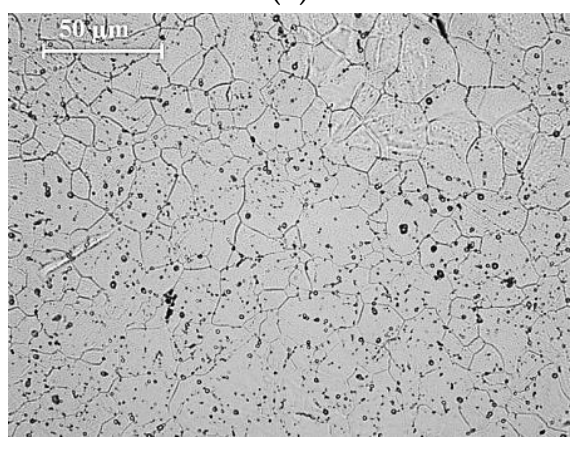

(c)

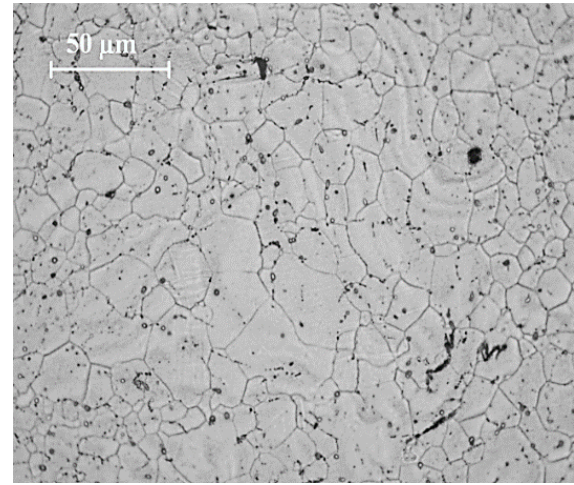

(b)

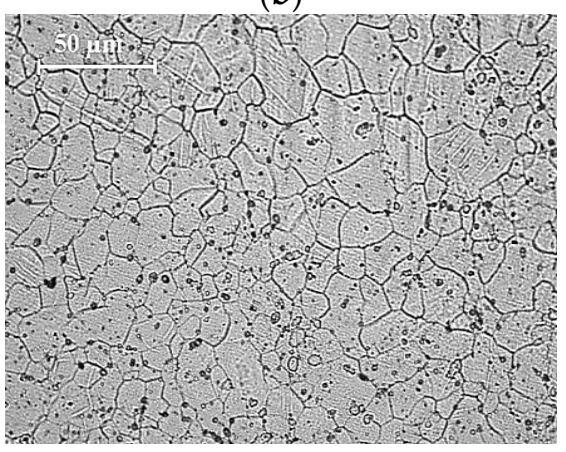

(d)

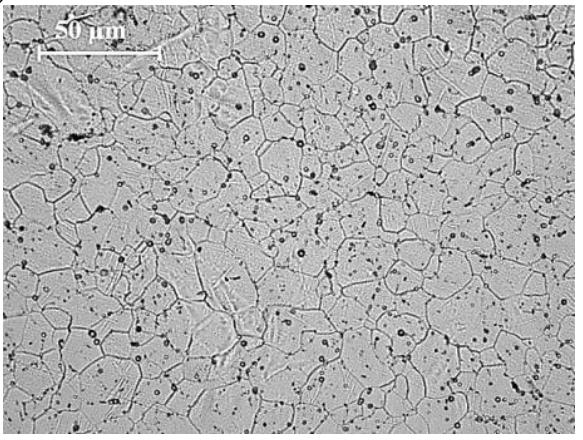

(e)

Figure 2. Microscopic images showing grain characteristics of: (a) pure magnesium; (b) Mg $0.58 \mathrm{TiN}$; (c) $\mathrm{Mg} 0.97 \mathrm{TiN}$; (d) Mg $1.98 \mathrm{TiN}$; and (e) Mg 2.5 TiN.

Table 3. Results of microstructure and microhardness studies.

\begin{tabular}{ccccc}
\hline S1. No & Material & Grain Size $\left(\times \mathbf{1 0}^{-6} \mathbf{m}\right)$ & Aspect Ratio $\left(\times \mathbf{1 0}^{-6} \mathbf{m}\right)$ & Microhardness (HV) \\
\hline 1 & $\mathrm{Mg}$ & $25.5 \pm 2$ & $1.25 \pm 0.2$ & $53 \pm 1$ \\
2 & $\mathrm{Mg} 0.58 \mathrm{TiN}$ & $23 \pm 2.5(\downarrow 9 \%)$ & $1.81 \pm 0.1$ & $56 \pm 1.5(\uparrow 6 \%)$ \\
3 & $\mathrm{Mg} 0.97 \mathrm{TiN}$ & $15 \pm 2.5(\downarrow 41 \%)$ & $1.28 \pm 0.2$ & $60 \pm 1.5(\uparrow 13 \%)$ \\
4 & $\mathrm{Mg} 1.98 \mathrm{TiN}$ & $13 \pm 3.5(\downarrow 49 \%)$ & $1.32 \pm 0.4$ & $65 \pm 2.5(\uparrow 23 \%)$ \\
5 & $\mathrm{Mg} 2.5 \mathrm{TiN}$ & $11 \pm 3.5(\downarrow 57 \%)$ & $1.35 \pm 0.4$ & $67 \pm 3(\uparrow 26 \%)$ \\
\hline
\end{tabular}




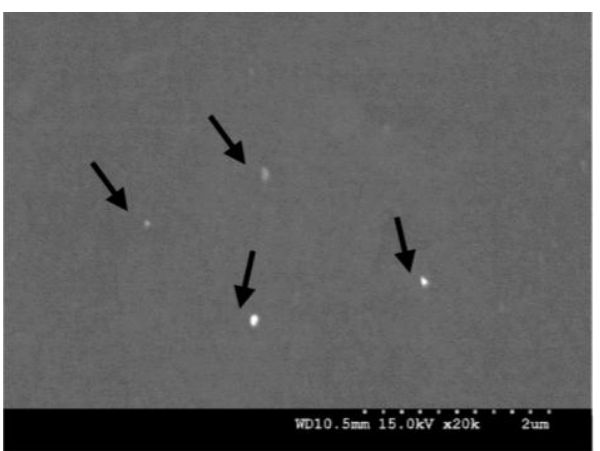

(a)

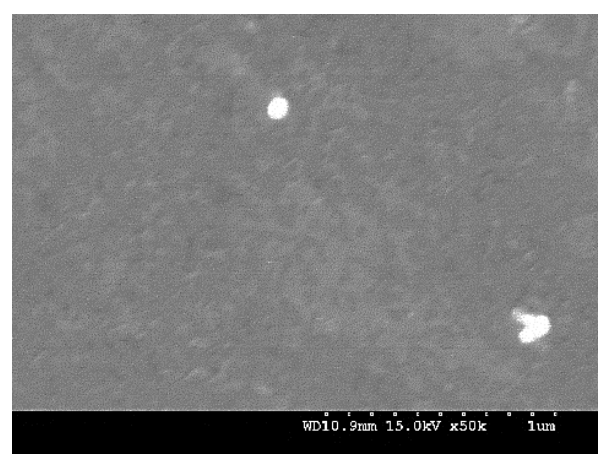

(b)

Figure 3. (a) Distribution of TiN NPs and (b) interfacial integrity of $\mathrm{Mg}$-TiN in $\mathrm{Mg} 2.5 \mathrm{vol.} \%$ TiN nanocomposite.

\subsection{Coefficient of Thermal Expansion (CTE)}

The CTE values of the synthesized pure $\mathrm{Mg}$ and $\mathrm{Mg}$-TiN nanocomposites measured in the temperature range of 50 to $400^{\circ} \mathrm{C}$ (Table 1) reveal that the average CTE values of the nanocomposites decreases with the addition of TiN NPs and thereby contribute more to the dimensional stability of pure Mg. Mg 2.5 vol. \% TiN nanocomposite exhibited a minimum CTE value of $\sim 22.61 \times 10^{-6} / \mathrm{K}$ which is $\sim 16 \%$ lower than that of pure $\mathrm{Mg}\left(27 \times 10^{-6} / \mathrm{K}\right)$.

\subsection{Microhardness Test}

The hardness values of pure Mg was found to increase with the addition of TiN NPs (Table 3) and $\mathrm{Mg} 2.5$ vol. \% TiN exhibited a maximum hardness value of $\sim 67 \mathrm{HV}$, which is $\sim 26 \%$ greater than that of pure $\mathrm{Mg}$ and, thereby, exhibit higher constraints to localized plastic deformation.

\subsection{Tensile Test}

The room temperature tensile properties of pure $\mathrm{Mg}$ and $\mathrm{Mg}$-TiN nanocomposites and their representative stress-strain curves are shown in Table 4 and Figure 4, respectively. The tensile strength properties of pure $\mathrm{Mg}$ was found to increase with the addition of $\geqslant$ (greater than or equal to) $0.97 \mathrm{vol} . \%$ TiN NPs and $\mathrm{Mg} 2.5$ vol. \% TiN exhibited the maximum $0.2 \%$ tensile yield strength $(0.2 \% \mathrm{TYS})$ and ultimate tensile strength (UTS) of $\sim 135 \mathrm{MPa}$ and $\sim 196 \mathrm{MPa}$, respectively, which is $\sim 26 \%$ and $\sim 17 \%$ greater than that of pure $\mathrm{Mg}$. The tensile fracture strain of pure $\mathrm{Mg}$ was found to increase with up to 1.98 vol. \% TiN (to $~ 15 \%$ ) and with further addition ( 2.5 vol. \%), the fracture strain value of pure $\mathrm{Mg}$ decreased to $10.6 \%$. Further, due to simultaneous improvements in the $0.2 \%$ TYS, UTS, and tensile fracture strain values of pure $\mathrm{Mg}$ observed with the addition of up to 1.98 vol. \% TiN NPs, a significant increase in the energy absorbed (EA) until failure under tensile loading is noticed, indicating improvement in their damage tolerant capabilities. Among the synthesized materials, $\mathrm{Mg} 1.98$ vol. \% TiN nanocomposite exhibited a maximum EA value of $\sim 26 \mathrm{MJ} / \mathrm{m}^{3}$, which is $\sim 85 \%$ greater than that of pure Mg.

Table 4. Results of room temperature tensile testing.

\begin{tabular}{ccccc}
\hline Material & $\mathbf{0 . 2} \%$ TYS (Mpa) & UTS (Mpa) & Fracture Strain (\%) & Energy absorbed (MJ/m $\mathbf{m}^{\mathbf{3}}$ ) \\
\hline Pure Mg & $107 \pm 5$ & $167 \pm 7$ & $10 \pm 1$ & $14 \pm 2$ \\
Mg 0.58 TiN & $91 \pm 5(\downarrow 15 \%)$ & $151 \pm 4(\downarrow 10 \%)$ & $15 \pm 1(\uparrow 50 \%)$ & $20 \pm 1(\uparrow 43 \%)$ \\
Mg 0.97 TiN & $112 \pm 2(\uparrow 5 \%)$ & $173 \pm 1(\uparrow 4 \%)$ & $15 \pm 2(\uparrow 50 \%)$ & $24 \pm 2.5(\uparrow 71 \%)$ \\
Mg 1.98 TiN & $130 \pm 7(\uparrow 21 \%)$ & $190 \pm 11(\uparrow 14 \%)$ & $14.5 \pm 1(\uparrow 45 \%)$ & $26 \pm 4(\uparrow 85 \%)$ \\
Mg 2.5 TiN & $135 \pm 8(\uparrow 26 \%)$ & $196 \pm 14(\uparrow 17 \%)$ & $10.6 \pm 1.2(\uparrow 5 \%)$ & $19.8 \pm 1(\uparrow 43 \%)$ \\
\hline
\end{tabular}




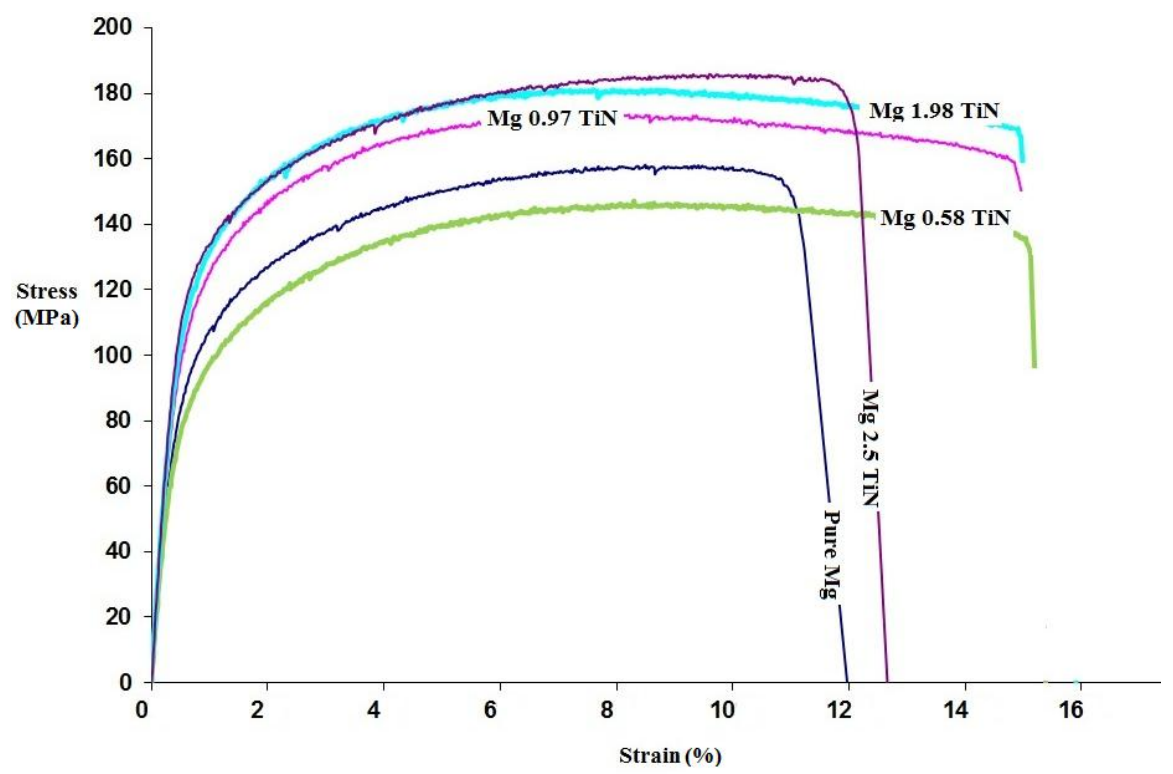

Figure 4. Stress-strain curve of Mg-TiN nanocomposites under tensile loading.

\subsection{Compression Test}

The room temperature compression properties of pure $\mathrm{Mg}$ and $\mathrm{Mg}$-TiN nanocomposites and their representative stress-strain curves are shown in Table 5 and Figure 5, respectively. The compression strength properties of pure $\mathrm{Mg}$ was found to increase with the addition of up to 1.98 vol. \% TiN NPs and $\mathrm{Mg} 1.98$ vol. \% TiN nanocomposite exhibited the maximum $0.2 \%$ compressive yield strength (0.2\% CYS) and ultimate compressive strength (UCS) of $\sim 103 \mathrm{MPa}$ and $\sim 385 \mathrm{MPa}$, respectively, which is $\sim 28 \%$ and $\sim 11 \%$ greater than that of pure Mg. With further addition of TiN NPs ( 2.5 vol. $\%$ ), the $0.2 \%$ CYS and UCS of the nanocomposite was found to decrease. Mg-TiN nanocomposites exhibited higher compressive fracture strain values $(\sim 21 \%)$ when compared to that of pure $\mathrm{Mg}(\sim 18.5 \%)$. Further, the energy absorbed (EA) until failure under compressive loading of pure $\mathrm{Mg}$ was found to increase due to the presence of TiN NPs and Mg 0.97 TiN nanocomposite exhibited a maximum EA value of $\sim 43 \mathrm{MJ} / \mathrm{m}^{3}$, which is $\sim 15 \%$ greater than that of pure $\mathrm{Mg}$.

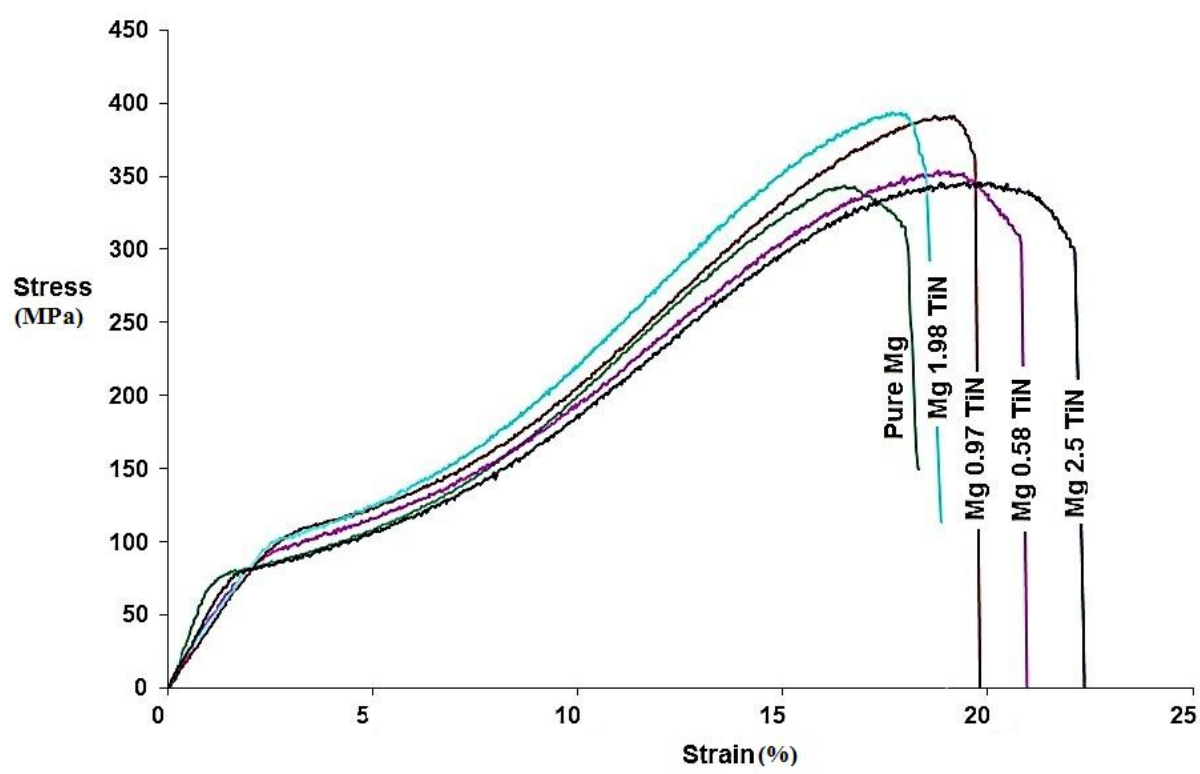

Figure 5. Stress-strain curve of $\mathrm{Mg}$-TiN nanocomposites under compression loading. 
Table 5. Results of room temperature compression testing.

\begin{tabular}{ccccc}
\hline Material & $\mathbf{0 . 2} \%$ CYS (Mpa) & UCS (Mpa) & Fracture Strain (\%) & Energy Absorbed (MJ $/ \mathbf{m}^{\mathbf{3}}$ ) \\
\hline Pure Mg & $80.4 \pm 2.5$ & $347 \pm 4$ & $18.5 \pm 1.5$ & $37.3 \pm 2$ \\
$\mathrm{Mg} 0.58 \mathrm{TiN}$ & $83.4 \pm 2(\uparrow 4 \%)$ & $355 \pm 8(\uparrow 2 \%)$ & $21(\uparrow 13 \%)$ & $42.5 \pm 2(\uparrow 14 \%)$ \\
$\mathrm{Mg} 0.97 \mathrm{TiN}$ & $101 \pm 3(\uparrow 26 \%)$ & $365.5(\uparrow 5 \%)$ & $20 \pm 1(\uparrow \%)$ & $43 \pm 1(\uparrow 15 \%)$ \\
$\mathrm{Mg} 1.98 \mathrm{TiN}$ & $103 \pm 5(\uparrow 28 \%)$ & $385 \pm 13(\uparrow 11 \%)$ & $20 \pm 1(\uparrow 7 \%)$ & $42 \pm 3(\uparrow 13 \%)$ \\
$\mathrm{Mg} 2.5 \mathrm{TiN}$ & $82 \pm 3$ & $345 \pm 1$ & $21 \pm 1.5(\uparrow 13 \%)$ & $42 \pm 1(\uparrow 12 \%)$ \\
\hline
\end{tabular}

\section{Discussion}

\subsection{Microstructural Characteristics}

During recrystallization, when compared to the presence of large sized reinforcements, ultrafine second phase reinforcements restrict the grain growth of metal matrix more significantly [14]. Figure 6 shows the influence of volume fraction and type of Ti NPs (metal and ceramics) on the grain size of pure Mg. The grain size of pure Mg was found to decrease with the addition of NPs which is due to (a) the ability of NPs to nucleate $\mathrm{Mg}$ grains during recrystallization and (b) restriction in the grain growth of pure $\mathrm{Mg}$ due to grain boundary pinning by NPs. It is observed that among the Mg nanocomposites containing Ti (metal) [15] and ceramics of Ti, TiX (where $\mathrm{X}=\mathrm{C}$ [16], $\mathrm{O}_{2}$ [17], $\mathrm{N}$ (present study), $\mathrm{B}_{2}$ [18]) NPs, Mg-Ti nanocomposites exhibited lowest grain size of $\sim 1.25 \mu \mathrm{m}$ with $1.98 \mathrm{vol}$. \% Ti addition and this may be due to good wetting of Ti by the molten $\mathrm{Mg}$ matrix [14]. In the present study, among the synthesized Mg-TiN nanocomposites, $\mathrm{Mg} 2.5$ vol. \% TiN exhibited a minimum grain size of $\sim 11 \mu \mathrm{m}$, which is $\sim 57 \%$ lower than that of pure $\mathrm{Mg}$. The fundamental principle behind the ability of ultrafine particulates within the metal matrix to nucleate recrystallized grains and inhibit grain growth has been established already $[19,20]$.

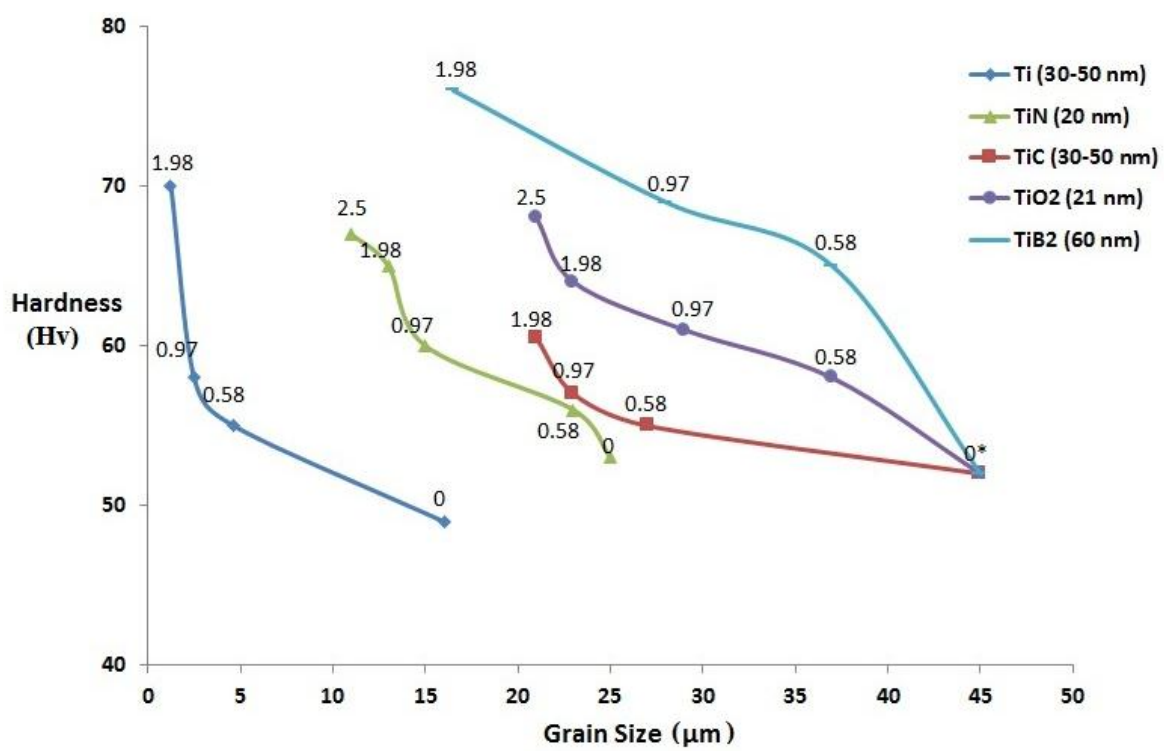

Figure 6. Influence of volume fraction and type of Ti nanoparticulates on the grain size and microhardness values of pure $\mathrm{Mg}$. Volume fraction of reinforcements are utilized as data labels and 0 indicate hardness values of pure $\mathrm{Mg}$ utilized for comparison in the case of $\mathrm{Mg}-\mathrm{TiC}, \mathrm{Mg}-\mathrm{TiB}_{2}$, and $\mathrm{Mg}-\mathrm{TiO}_{2}$ nanocomposites.

The effects of TiN NPs on the crystallographic orientation of pure Mg were analyzed utilizing $\mathrm{X}$-ray diffraction studies. Along the transverse direction of the extruded $\mathrm{Mg}$ samples, dominance of prismatic intensity $\left(2 \theta=32^{\circ}\right)$ was observed indicating that any of the prismatic planes is perpendicular to the extrusion direction $[16,17,19]$. Along the longitudinal direction, the intensity corresponding to 
the basal plane $\left(2 \theta=34^{\circ}\right)$ of hot extruded pure $\mathrm{Mg}$ was found to be the maximum indicating strong basal texture with most of the basal planes parallel to the extrusion direction, which is commonly found in wrought $\mathrm{Mg}$ materials [16,19,21]. With the addition of up to $1.98 \mathrm{vol}$. \% TiN NPs, the basal plane intensity of pure $\mathrm{Mg}$ was found to decrease indicating that the basal planes are no longer parallel to the extrusion direction. This similar randomization in the texture of pure $\mathrm{Mg}$ with the addition of certain critical quantities of NPs, such as $(0.58$ and 0.97$)$ vol. \% $\mathrm{TiB}_{2},(0.58$ and 0.97$)$ vol. \% $\mathrm{TiC}$ and $(0.58,0.97,1.98)$ vol. $\% \mathrm{TiO}_{2}$ was observed previously $[16,17,19]$. With further addition of $\mathrm{TiN}$ NPs (2.5 vol. \%), the basal plane intensity of pure Mg was found to increase and thereby exhibiting strong basal texture $\left(\mathrm{I}_{\mathrm{basal}} / \mathrm{I}_{\max }=1\right)$ similar to that of monolithic pure Mg. Unlike ceramics of Ti, addition of Ti (metal) NPs did not contribute to the textural changes of pure Mg [15].

\subsection{Mechanical Properties}

\subsubsection{Microhardness}

In the present study, the hardness value of pure $\mathrm{Mg}$ was found to increase with the addition of TiN NPs and Mg 2.5 TiN exhibited the maximum hardness value of $\sim 67 \mathrm{HV}$. Figure 6 shows the influence of the volume fraction and type of Ti NPs (metal and ceramics) on the microhardness values of pure $\mathrm{Mg}$. Within the $\mathrm{Mg}$-Ti based nanocomposite systems such as $\mathrm{Mg}-\mathrm{Ti}, \mathrm{Mg}-\mathrm{TiB}_{2}, \mathrm{Mg}-\mathrm{TiC}$, and $\mathrm{Mg}-\mathrm{TiO}_{2}$, it is observed that the hardness value of pure $\mathrm{Mg}$ increases with (a) increasing volume fraction of NPs and (b) decrease in the grain size. A similar trend in the microhardness values was observed in the $\mathrm{Mg}$-TiN system. Among the $\mathrm{Mg}$ nanocomposites, $\mathrm{Mg} 1.98$ vol. $\% \mathrm{TiB}_{2}$ exhibited the maximum hardness value of $76 \mathrm{HV}$ which may be due to (a) the presence of harder $\mathrm{TiB}_{2} \mathrm{NPs}$ of hardness value $\sim 960 \mathrm{HV}$ or $\sim 34 \mathrm{GPa}$ [22] (Table 6), (b) relatively larger NPs size $(\sim 60 \mathrm{~nm})$, which may assist in more effective load bearing creating constraint to localized plastic deformation, and (c) for NPs of size less than $80 \mathrm{~nm}$, dispersion of NPs is inversely proportional to its size and among the NPs, $\mathrm{TiB}_{2}(60 \mathrm{~nm})$ has more possibility for relatively more uniform dispersion within the Mg metal matrix [23].

Table 6. Properties of $\mathrm{Ti}$ (metal) and ceramics of $\mathrm{Ti}\left(\mathrm{TiB}_{2}, \mathrm{TiC}, \mathrm{TiN}, \mathrm{TiO}_{2}\right)$.

\begin{tabular}{|c|c|c|c|c|c|c|c|}
\hline \multirow[b]{2}{*}{$\begin{array}{l}\text { Reinforcement or } \\
\text { Nanoparticulates }\end{array}$} & \multicolumn{7}{|c|}{ Properties } \\
\hline & $\begin{array}{l}\text { Crystal } \\
\text { Type }\end{array}$ & $\begin{array}{l}\text { Density } \\
\text { (g/cc) }\end{array}$ & $\begin{array}{c}\text { Average } \\
\text { Particle Size } \\
\text { Utilized in } \mathrm{Mg} \\
\text { MMNC (nm) }\end{array}$ & $\begin{array}{c}\text { Melting } \\
\text { point }\left({ }^{\circ} \mathrm{C}\right)\end{array}$ & $\begin{array}{l}\text { Young's } \\
\text { modulus } \\
(\mathrm{GPa})\end{array}$ & $\begin{array}{c}\text { Vicker's } \\
\text { hardness } \\
(\mathrm{GPa})\end{array}$ & $\begin{array}{c}\text { CTE } \\
\left(10^{-6} / \mathrm{K}\right)\end{array}$ \\
\hline Ti [24] & hcp & 4.5 & 40 & 1667 & 120 & $0.830-3.420$ & 8.9 \\
\hline $\mathrm{TiB}_{2}[25,26]$ & Hexagonal & 4.52 & 60 & 2790 & 530 & 34 & 7.9 \\
\hline $\mathrm{TiC}[27]$ & Cubic & 4.93 & 40 & 3067 & $300-480$ & $29-32$ & 7.4 \\
\hline $\mathrm{TiO}_{2}[28]$ & tetragonal & 4.23 & 21 & 1843 & 230 & $7-11$ & 9 \\
\hline TiN [28] & Cubic & 5.22 & 20 & 2930 & 390 & 24 & 9.35 \\
\hline
\end{tabular}

\subsubsection{Tensile Properties}

In the present study, among the synthesized Mg-TiN nanaocomposites, $\mathrm{Mg} 2.5 \mathrm{vol} . \% \mathrm{TiN}$ exhibited the maximum $0.2 \%$ TYS and UTS of $\sim 135 \mathrm{MPa}$ and $\sim 196 \mathrm{MPa}$, respectively. The strength of pure $\mathrm{Mg}$ was found to increase with the addition of $\geqslant$ (greater than or equal to) 0.97 vol. $\%$ TiN NPs. The major mechanisms contributing to the strengthening of particulate reinforced metal matrix nanocomposites (MMNCs) are [29] (a) Orowan strengthening from dislocation bowing of NPs, (b) Hall-Petch strengthening from grain refinement, (c) Forest strengthening resulting from the mismatch in the coefficient of thermal expansion values between the metal matrix and NPs, (d) Taylor strengthening due to the mismatch in the modulus values between the metal matrix and NPsm, and (e) strengthening due to load bearing of the NPs.

The presence of NPs within the metal matrix tends to form dislocation loops around the NPs and thereby offer resistance to dislocation movement and assist in strengthening of MMNCs. 
This strengthening mechanism observed in MMNCs is termed as Orowan strengthening. The strength improvement due to the Orowan effect of particulate reinforcement within the $\mathrm{Mg}$ matrix is given by the Orowan-Ashby equation as shown in Equation (1) [30]:

$$
\sigma_{\text {Orowan }}=\frac{0.13 \mathrm{~Gb}}{\lambda} \ln \frac{r}{b}
$$

where, $\mathrm{G}$ is the shear modulus of $\mathrm{Mg}$ (17.3 GPa) [31]; $\mathrm{b}$ is the Burgers vector of $\mathrm{Mg}\left(3.21 \times 10^{-10} \mathrm{~m}\right)$ [32]; $r$ and $d_{p}$ are the average radius and diameter of NPs, respectively. The interparticulate spacing $(\lambda)$ between the NPs within the Mg metal matrix is given by Equation (2) [33,34]:

$$
\lambda=d_{p}\left[\left(\frac{1}{2 V_{p}}\right)^{\frac{1}{3}}-1\right]
$$

where, $V_{p}$ is the volume fraction addition of Ti-based NPs.

The influence of particulate size and volume fraction of reinforcements on the interparticulate spacing $(\lambda)$ and Orowan strengthening contribution ( $\sigma_{\text {Orowan }}$ ) towards $0.2 \% \mathrm{TYS}$ of Mg-Ti based nanocomposites is shown in Table 7 . In the case of $\mathrm{Mg} 0.58 \mathrm{TiN}$ nanocomposite, to realize $\sigma_{\text {Orowan }}$ of $\sim 37 \mathrm{MPa}$, TiN NPs need to be uniformly distributed with an average interparticulate spacing of $\sim 68 \mathrm{~nm}$. With a further increase in the volume fraction of TiN NPs, the value of $\lambda$ decreases and, for $\mathrm{Mg} 2.5 \mathrm{vol}$. \% TiN, a $\lambda$ of $34.20 \mathrm{~nm}$ is to be achieved to realize an $\sigma_{\text {Orowan }}$ of $\sim 73 \mathrm{MPa}$. Experimentally, it is difficult to achieve uniform distribution of NPs with $\lambda$ closer to the theoretically-predicted values in the range of nm scale lengths. The effectiveness of synthesis methodology in the dispersion of NPs within the metal matrix play a vital role in composite technology and, failing which clustering of NPs take place, that (a) affecting mean effective particulate size within the metal matrix leading to distribution of particle sizes and (b) randomized $\lambda$ values within the metal matrix may be observed. In the case of adopted synthesis methodology (disintegrated melt deposition technique, DMD), stirring parameters play a vital role in controlling the clustering effects within the composites. The density of Ti-based reinforcements utilized for synthesizing Mg nanocomposites (Table 6) was found to be in the range of $\sim 4.5$ to $5.25 \mathrm{~g} / \mathrm{cc}$ indicating minimal or no significant changes and with the adopted synthesis methodology utilizing constant stirring parameters ( $465 \mathrm{rpm}$ for $6 \mathrm{~min}$ ) make the study a fair comparison among the $\mathrm{Mg}$-Ti based nanocomposites. Theoretically, for a constant volume fraction,

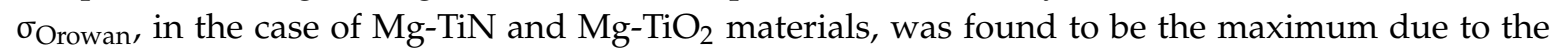
presence of lower particulate size of $\sim 20 \mathrm{~nm}$ and $\sim 21 \mathrm{~nm}$, respectively. Previously, the authors studied the effect of synthesis methodology (DMD) on the dispersion of $\mathrm{TiO}_{2} \mathrm{NPs}_{\text {s }}$ by experimentally measuring the value of $\lambda$. It was found that the presence of $\mathrm{TiO}_{2} \mathrm{NPs}$ of size $\sim 21 \mathrm{~nm}$ contributed only $\sim 4 \mathrm{MPa}$ and $\sim 7 \mathrm{MPa}$ to the $0.2 \%$ TYS in the case of $\mathrm{Mg}$ (1.98 and 2.5) vol. \% $\mathrm{TiO}_{2}$ nanocomposites, respectively. Therefore, in the case of Mg-TiN nanocomposites with TiN NPs of size and density ( $20 \mathrm{~nm}$ and $5.22 \mathrm{~g} / \mathrm{cc})$ closer to that of $\mathrm{TiO}_{2} \mathrm{NPs}(\sim 21 \mathrm{~nm}$ and $4.23 \mathrm{~g} / \mathrm{cc})$, the Orowan strengthening contribution $\left(\sigma_{\text {Orowan }}\right)$ may be considered almost negligible.

Grain size of a material is inversely proportional to its tensile yield strength (TYS) and the strengthening effect relating the grain size to the strength of the material is termed as Hall-Petch Strengthening. The following equation describes the Hall-Petch equation:

$$
\sigma_{\text {Hall-Petch }}=K D^{-0.5}
$$

where, $K$ is the Hall-Petch coefficient of $\mathrm{Mg}\left(280 \mathrm{MPa} \mu \mathrm{m}^{1 / 2}\right)$ and $D$ is the average grain size of synthesized $\mathrm{Mg}$ nanocomposites. Further, the relationship between reinforcement particulate 
size, volume fraction of particulates, and grain size of composites is given by Zener equation, Equation (4) [35]:

$$
d_{m}=\frac{4 \alpha d_{p}}{3 v_{p}}
$$

where, $\alpha$ is proportionality constant; $d_{p}$ is the average diameter of the NPs; $v_{p}$ is the volume fraction of $\mathrm{NPs}$; and $d_{m}$ is the grain size of the metal matrix.

Table 7. Orowan strengthening contribution towards $0.2 \%$ TYS of Ti based NPs reinforced Mg nanocomposites.

\begin{tabular}{|c|c|c|c|c|c|}
\hline \multirow{2}{*}{$\begin{array}{c}\text { Volume } \\
\text { Fraction (\%) }\end{array}$} & \multirow{2}{*}{$\begin{array}{c}\text { Orowan Stress } \sigma_{\text {Orowan }} \\
(\mathrm{MPa}) \text { and Interparticulate } \\
\text { Spacing } \lambda(\mathrm{nm})\end{array}$} & \multicolumn{4}{|c|}{ Reinforcement Size (in nm) } \\
\hline & & $\begin{array}{c}\text { TiN (20 nm) } \\
\text { (Present study) }\end{array}$ & $\begin{array}{c}\mathrm{TiO}_{2} \\
(21 \mathrm{~nm})\end{array}$ & $\begin{array}{l}\text { Ti and } \mathrm{TiC} \\
(40 \mathrm{~nm})\end{array}$ & $\begin{array}{c}\mathrm{TiB}_{2} \\
(60 \mathrm{~nm})\end{array}$ \\
\hline \multirow{2}{*}{0.58} & $\sigma_{\text {Orowan }}$ & 36.83 & 35.08 & 18.41 & 12.27 \\
\hline & $\lambda$ & 68.30 & 71.70 & 337.00 & 205.00 \\
\hline \multirow{2}{*}{0.97} & $\sigma_{\text {Orowan }}$ & 46.25 & 44.05 & 23.12 & 15.41 \\
\hline & $\lambda$ & 54.40 & 57.10 & 108.00 & 163.00 \\
\hline \multirow{2}{*}{1.98} & $\sigma_{\text {Orowan }}$ & 65.09 & 62.00 & 32.54 & 21.69 \\
\hline & $\lambda$ & 38.70 & 40.60 & 77.30 & 116.00 \\
\hline \multirow{2}{*}{2.5} & $\sigma_{\text {Orowan }}$ & 73.42 & 69.93 & \multirow{2}{*}{\multicolumn{2}{|c|}{ NA }} \\
\hline & $\lambda$ & 34.20 & 36.03 & & \\
\hline
\end{tabular}

Table 8 shows the contribution of Hall-Petch $\left(\sigma_{\text {Hall-Petch }}\right)$ and Orowan strengthening $\left(\sigma_{\text {Orowan }}\right)$ due to the presence of Ti-based NPs to the TYS of pure Mg. Among the Mg-Ti based nanocomposites, $\sigma_{\text {Hall-Petch }}$ values corresponding to Ti (metal) NPs were found to be the maximum with Mg 1.98 vol. \% Ti exhibiting $\sigma_{\text {Hall-Petch }}$ as high as $\sim 250.4 \mathrm{MPa}$. This increase in the $\sigma_{\text {Hall-Petch }}$ contribution observed with Mg-Ti materials is attributed to the significant grain refinement with $\mathrm{Mg} 1.98$ vol. \% Ti exhibiting the lowest grain size of $\sim 1.25 \mu \mathrm{m}$. The $\sigma_{\text {Hall-Petch }}$ was found to increase with (a) lower particulate size and (b) higher volume fraction addition of NPs. Among the ceramics of Ti, TiN was more effective towards $\sigma_{\text {Hall-Petch }}$ contribution and $\mathrm{Mg} 2.5$ vol. \% TiN exhibited the maximum $\sigma_{\text {Hall-Petch }}$ contribution of $\sim 84 \mathrm{MPa}$.

Table 8. Theoretical contribution of Orowan and Hall-Petch strengthening mechanisms to the $0.2 \%$ TYS of Mg-Ti-based nanocomposites.

\begin{tabular}{|c|c|c|c|c|}
\hline Material & $\begin{array}{c}\text { Volume Fraction } \\
(\%)\end{array}$ & $\begin{array}{c}\text { Experimental } \\
0.2 \% \mathrm{TYS}(\mathrm{MPa})\end{array}$ & $\sigma_{\text {Orown }}(\mathbf{M P a})$ & $\sigma_{\text {Hall-Peth }}(\mathbf{M P a})$ \\
\hline \multirow{3}{*}{$\mathrm{Mg}-\mathrm{Ti}$} & 0.58 & 134.00 & 18.41 & 130.00 \\
\hline & 0.97 & 135.00 & 23.12 & 177.10 \\
\hline & 1.98 & 162.00 & 32.54 & 250.40 \\
\hline \multirow{3}{*}{$\mathrm{Mg}-\mathrm{TiB}_{2}$} & 0.58 & 93.00 & 12.27 & 46.03 \\
\hline & 0.97 & 110.00 & 15.41 & 52.91 \\
\hline & 1.98 & 140.00 & 21.69 & 68.93 \\
\hline \multirow{3}{*}{$\mathrm{Mg}-\mathrm{TiC}$} & 0.58 & 94.00 & 18.41 & 53.88 \\
\hline & 0.97 & 87.00 & 23.12 & 58.34 \\
\hline & 1.98 & 125.00 & 32.54 & 61.10 \\
\hline \multirow{4}{*}{$\mathrm{Mg}-\mathrm{TiO}_{2}$} & 0.58 & 80.00 & 35.08 & 46.03 \\
\hline & 0.97 & 97.00 & 44.05 & 52.00 \\
\hline & 1.98 & 102.00 & 62.00 & 58.38 \\
\hline & 2.50 & 124.00 & 69.93 & 61.10 \\
\hline \multirow{4}{*}{$\begin{array}{c}\text { Mg-TiN } \\
\text { (Present study) }\end{array}$} & 0.58 & 91.00 & 36.83 & 58.38 \\
\hline & 0.97 & 112.00 & 46.25 & 72.30 \\
\hline & 1.98 & 130.00 & 65.09 & 77.65 \\
\hline & 2.50 & 135.00 & 73.42 & 84.42 \\
\hline
\end{tabular}


Strengthening due to load bearing $\left(\sigma_{L T}\right)$ or transferring of applied load to NPs within the metal matrix is given by the following equation:

$$
\sigma_{L T}=0.5 v_{p} \sigma_{M g}
$$

where, $\sigma_{M g}$ is the experimental $0.2 \%$ TYS of pure Mg; and $\sigma_{L T}$ depends on the volume fraction of NPs added to the metal matrix. In the case of $\operatorname{Mg}(0.58,0.97,1.98$, and 2.5$)$ vol. \% TiN nanocomposites, $\sigma_{L T}$ was found to be $\sim 0.23 \mathrm{MPa}, \sim 0.38 \mathrm{MPa}, \sim 0.79 \mathrm{MPa}$, and $\sim 1 \mathrm{MPa}$, respectively, which are insignificant and, therefore, the contribution of strengthening due to load bearing is negligible in the case of low-volume fraction reinforced Mg MMNCs.

Forest strengthening, or strengthening due to CTE mismatch $\left(\sigma_{C T E}\right)$ between the $\mathrm{Mg}$ matrix and NPs, leads to increase in the dislocation density by generation of dislocations nearby the NPs. Taylor strengthening, or strengthening due to mismatch in the modulus values between the Mg matrix and NPs $\left(\sigma_{E M}\right)$, leads to formation of geometrically-necessary dislocations (GND) due to straining or the presence of external load, and is profound only with higher volume fraction NPs addition. The CTE and modulus values of Ti-based reinforcements are shown in Table 6. Previously, it was experimentally found that in the case of MMNCs with low volume fraction ( $<10 \mathrm{vol}$. \%) NPs of size less than $80 \mathrm{~nm}$, the Forest strengthening contribution is almost negligible [23,36,37]. When compared to the contributions of other strengthening mechanisms, the contributions from Taylor strengthening is also considered negligible $[29,38]$.

Figure 7 shows the influence of volume fraction and type of Ti reinforcement on the strength and fracture strain values of $\mathrm{Mg}$ nanocomposites under tensile loading. It is observed that presence of Ti (ceramic) NPs within the Mg metal matrix significantly improve the tensile fracture strain value of pure $\mathrm{Mg}$ when compared to that of Ti (metal) NPs and among the Mg MMNCs containing Ti-based reinforcements, $\mathrm{Mg} 0.97 \mathrm{TiC}$ exhibited the maximum tensile fracture strain value of $\sim 22 \%$. Improvement in the tensile fracture strain values in the case of Mg MMNCs containing Ti ceramics (brittle phases) NPs is due to the ability of the ultrafine particulates to weaken the basal texture of pure $\mathrm{Mg}$ which is observed through X-ray diffraction studies. In the present study, $\mathrm{Mg}(0.58,0.97$, and 1.98) TiN exhibited the maximum tensile fracture strain values of $\sim 15 \%$, which is $\sim 50 \%$ greater than that of pure $\mathrm{Mg}(\sim 10 \%)$. With further addition of TiN NPs ( $2.5 \mathrm{vol} . \%)$, strong basal texture similar to that of pure $\mathrm{Mg}$ was observed with a decrease in its tensile fracture strain value to $\sim 10.5 \%$.

The fracture surfaces of $\mathrm{Mg}$-TiN nanocomposites are discussed with representative fractograph images of pure $\mathrm{Mg}$ and $\mathrm{Mg} 2.5 \mathrm{TiN}$ nanocomposite after tensile loading as shown in Figure 8. For all pure $\mathrm{Mg}$ and $\mathrm{Mg}$-TiN nanocomposites, a typical cleavage mode of fracture is observed which indicates that the fracture behavior of $\mathrm{Mg}$-TiN materials is greatly controlled by pure Mg matrix. 

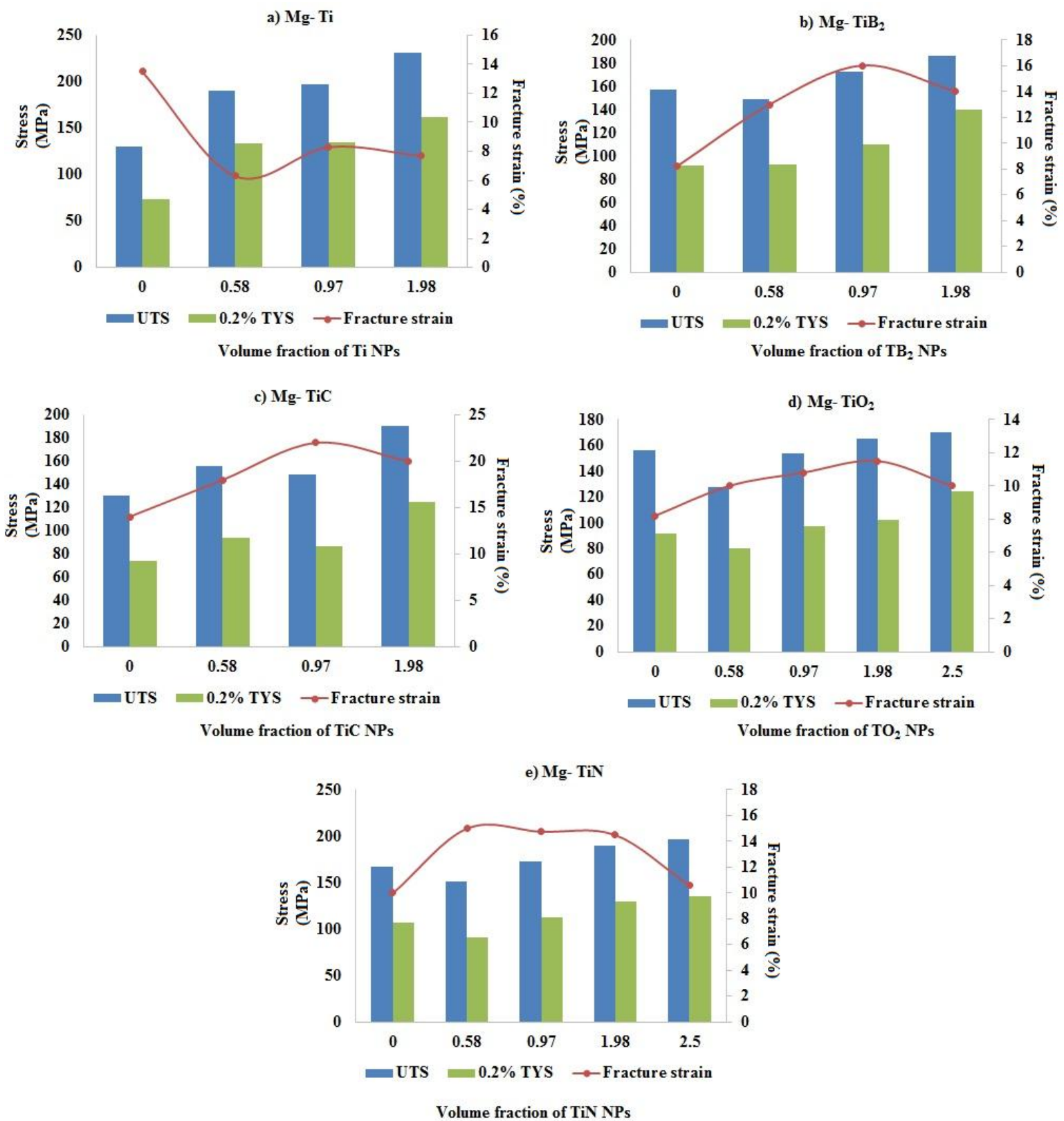

Figure 7. Influence of volume fraction and type of Ti nano-reinforcement on the tensile properties of pure $\mathrm{Mg}$. (a) $\mathrm{Mg}-\mathrm{Ti}$; (b) $\mathrm{Mg}_{-} \mathrm{TiB}_{2}$; (c) $\mathrm{Mg}-\mathrm{TiC}$; (d) $\mathrm{Mg}^{-\mathrm{TiO}_{2}}$; (e) $\mathrm{Mg}-\mathrm{TiN}$.

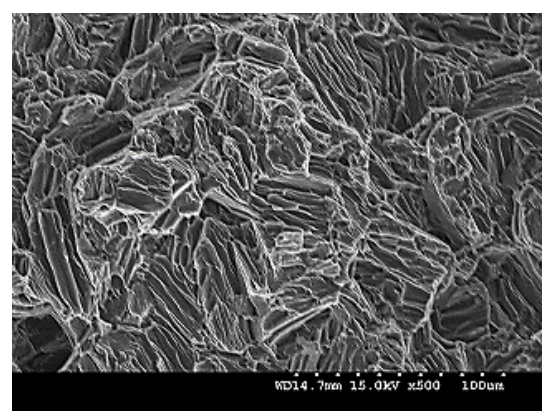

(a)

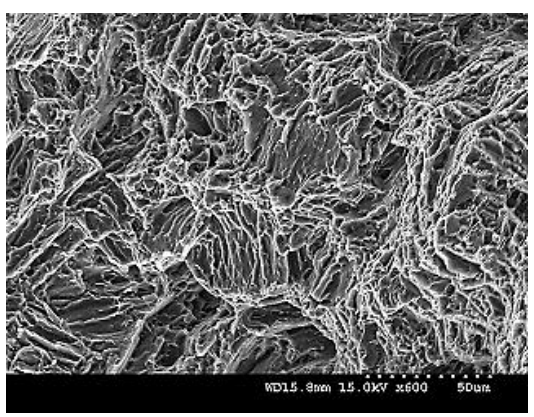

(b)

Figure 8. Fractographs of (a) pure $\mathrm{Mg}$ and (b) Mg 2.5 TiN under tensile loading. 


\subsubsection{Compressive Properties}

Figure 9 shows the influence of Ti-based NPs on the compressive properties of pure $\mathrm{Mg}$. The error bars with lower and upper limits indicate the $0.2 \%$ CYS and UCS of Mg-Ti-based nanocomposites, respectively. The presence of $\mathrm{Ti}$ (metal) NPs within the Mg metal matrix was found to significantly improve the strength properties of pure $\mathrm{Mg}$ under compression loading. The improvement in the strength properties of $\mathrm{Mg}$ - $\mathrm{Ti}$ (metal) nanocomposites may be due to significant grain refinement contributing to Hall-Petch strengthening. Mg 0.97 vol. \% Ti exhibited the highest compression strength properties of $\sim 130 \mathrm{MPa}(0.2 \% \mathrm{CYS})$ and $\sim 43 \mathrm{MPa}$ (UCS), respectively. The compressive strain values of $\mathrm{Mg}$-Ti (metal) nanocomposites were found to be lower than that of pure $\mathrm{Mg}(\sim 18 \%)$. When compared to Ti (metal) NPs, the presence of Ti (ceramic) NPs significantly improved the compressive fracture strain values of pure $\mathrm{Mg}$. Among the Ti (ceramics) NPs, Mg 1.98 vol. \% TiN exhibited the maximum compressive strength properties of $\sim 103 \mathrm{MPa}(0.2 \% \mathrm{CYS})$ and $\sim 385 \mathrm{MPa}$ (UCS), respectively, and $\mathrm{Mg}$ (0.58 and 0.97 ) TiC exhibited the maximum compressive fracture strain value of $\sim 22.5 \%$.
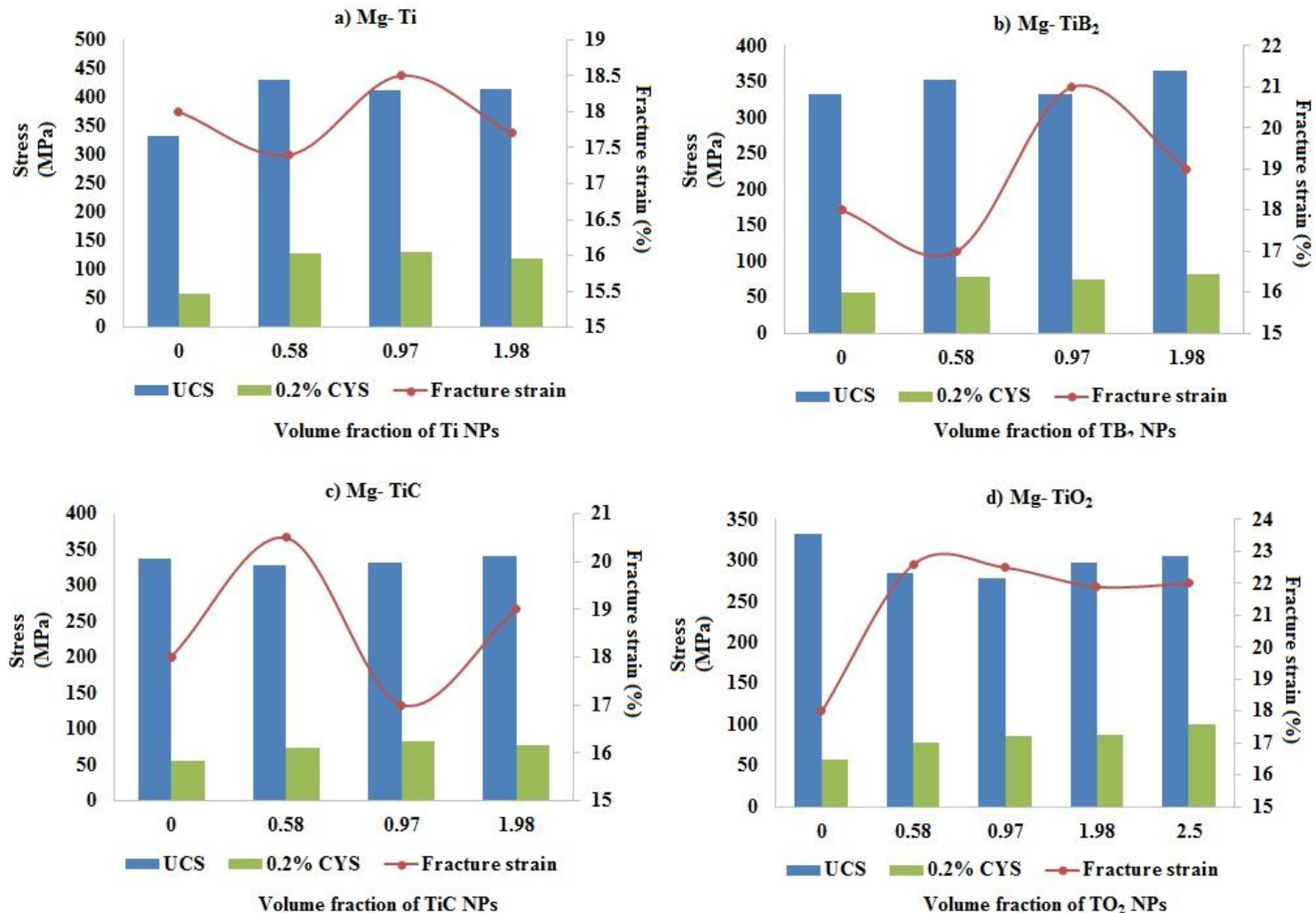

d) $\mathrm{Mg}-\mathrm{TiO}_{2}$
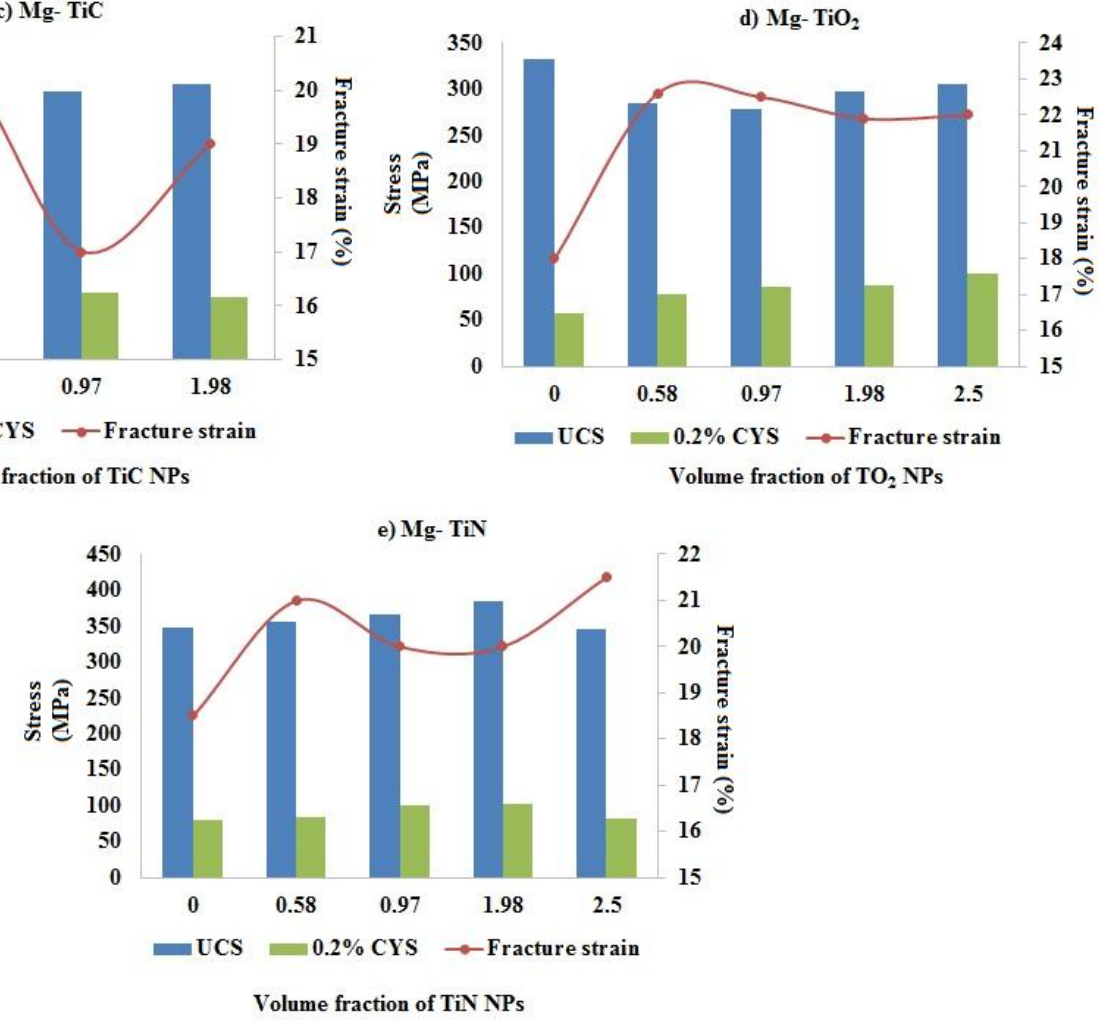

Figure 9. Influence of volume fraction and type of Ti nano-reinforcement on the compressive properties of pure $\mathrm{Mg}$. (a) $\mathrm{Mg}-\mathrm{Ti}$; (b) $\mathrm{Mg}-\mathrm{TiB}_{2} ;$ (c) $\mathrm{Mg}-\mathrm{TiC}$; (d) $\mathrm{Mg}_{-}-\mathrm{TiO}_{2}$; (e) $\mathrm{Mg}-\mathrm{TiN}$. 
In the present study, the strength and fracture strain values of $\mathrm{Mg}$-TiN nanocomposites under compression loading was found to increase with the addition of up to $1.98 \mathrm{vol}$. \% TiN and Mg 1.98 vol. \% TiN exhibited the maximum $0.2 \%$ CYS, UCS, and compressive fracture strain values of $\sim 103 \mathrm{MPa}, \sim 385 \mathrm{MPa}$, and $\sim 20 \%$, respectively. The increase in the strength properties of Mg-TiN nanocomposites under compression is due to the contribution of Hall-Petch strengthening and $\mathrm{Mg}$ $1.98 \mathrm{vol} . \%$ TiN with a lower grain size of $\sim 13 \mu \mathrm{m}$ exhibited the highest compression strength properties. With further addition of TiN NPs (2.5 vol. \%), compressive fracture strain values of the nanocomposite was found to increase with decrease in the strength properties $(0.2 \%$ CYS and UCS) which may be due to: (a) presence of possible agglomeration sites within the nanocomposite and (b) strong basal texture observed with Mg 2.5 vol. \% TiN similar to that of pure Mg. From Table 7, it can be observed that it is relatively difficult to uniformly disperse $2.5 \mathrm{vol}$. \% TiN NPs of size $20 \mathrm{~nm}$ within the Mg matrix with an interparticulate spacing $(\lambda)$ of $\sim 34.20 \mathrm{~nm}$ when compared to that of lower volume fraction of $\mathrm{Mg}$ $(0.58,0.97,1.98)$ vol. \% TiN nanocomposites.

The fracture surfaces of $\mathrm{Mg}$-TiN nanocomposites are discussed with representative fractograph images of pure $\mathrm{Mg}$ and $\mathrm{Mg} 2.5 \mathrm{TiN}$ nanocomposite after compressive loading, as shown in Figure 10. It is observed that failure in pure $\mathrm{Mg}$ and $\mathrm{Mg}$-TiN nanocomposites occurred at $45^{\circ}$ with respect to the compression loading axis and their representative fractographs indicate the presence of shear bands.

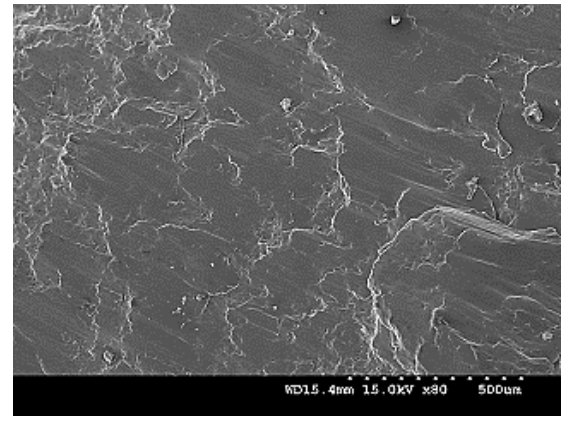

(a)

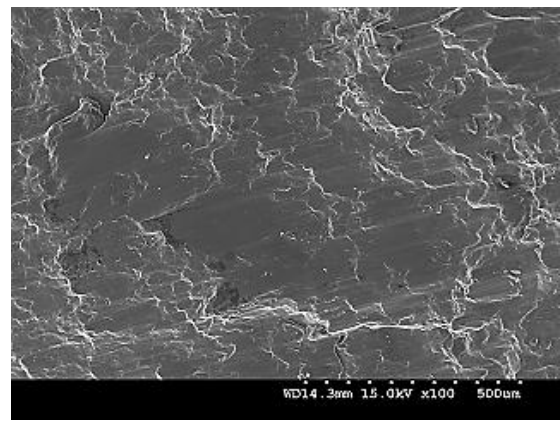

(b)

Figure 10. Fractographs of (a) Pure Mg and (b) Mg 2.5 TiN under compressive loading.

The tensile deformation of $\mathrm{Mg}$ materials is governed by slip mode with basal slip as the most dominant mechanism [18]. However, under compression, the initial deformation of $\mathrm{Mg}$ materials is by tensile twinning as the critically-resolved shear stress required to initiate basal slip under compression is more than that of twinning [18]. The directional nature of twinning makes $\mathrm{Mg}$ materials exhibit large anisotropy when deformed under different stress states and initial textures [39,40]. A way to capture the anisotropy in Mg materials is by measuring tensile-compression asymmetry (TCA) value which is given by $\sigma_{\mathrm{y}, \mathrm{t}} / \sigma_{\mathrm{y}, \mathrm{c}}$ where $\sigma_{\mathrm{y}, \mathrm{t}}$ and $\sigma_{\mathrm{y}, \mathrm{c}}$ are the uniaxial $0.2 \%$ yield strength of $\mathrm{Mg}$ materials under tensile and compression loading, respectively. In the case of $\mathrm{Mg}$-Ti (metal) nanocomposites, with addition of 1.98 vol. \% Ti, TCA value increased significantly, which is representative from its tensile fracture strain value of only $\sim 7.7 \%$. Strengthening in the case of $\mathrm{Mg}$-Ti (metal) nanocomposites was observed with significant decrease in the tensile fracture strain values. Whereas in the case of Mg-Ti (ceramic) NPs, the TCA value was found to decrease with up to certain critical quantity of NPs addition and with further addition of NPs, the TCA value of Mg nanocomposite was found to, once again, increase with the reduction in the tensile fracture strain values. Table 9 shows the TCA values of Mg-TiN nanocomposites. It is observed that with addition of up to $1.98 \mathrm{vol}$. \% TiN, TCA value of $\mathrm{Mg}$-TiN nanocomposites was found to decrease and $\mathrm{Mg} 0.58$ TiN exhibited a minimum TCA value of $\sim 1.09$. Weakening of strong basal texture of pure $\mathrm{Mg}$ which allows non-basal cross-slip to occur is possible in the case of $\mathrm{Mg}(0.58,0.97$, and 1.98) vol. \% TiN nanocomposites and under tensile loading, only marginal improvement in the $0.2 \%$ TYS is possible. For this reason, the $0.2 \%$ TYS of Mg 0.58 TiN was found to be $\sim 91 \mathrm{MPa}$, which is $\sim 15 \%$ lower than that of pure $\mathrm{Mg}$ exhibiting a higher tensile 
fracture strain value of $\sim 15 \%$. Among the $\mathrm{Mg}$-TiN nanocomposites, $\mathrm{Mg}(0.58,0.97$, and 1.98$)$ vol. $\%$ TiN exhibited the maximum tensile fracture strain values of $\sim 14$ to $15 \%$. With further addition of TiN NPs (2.5 vol. \%), the TCA value of pure Mg was found to increase to 1.64 which is representative from its tensile fracture strain value of only $\sim 10.6 \%$ similar to that of pure $\mathrm{Mg}(\sim 10 \%)$.

Table 9. TCA value of synthesized Mg-TiN nanocomposites.

\begin{tabular}{cccc}
\hline Material & $\mathbf{0 . 2} \%$ TYS & $\mathbf{0 . 2} \%$ CYS & TCA \\
\hline Pure Mg & $107 \pm 5$ & $80.4 \pm 2.5$ & 1.33 \\
Mg 0.58 TiN & $91 \pm 5$ & $83.4 \pm 2$ & 1.09 \\
Mg 0.97 TiN & $112 \pm 2$ & $101 \pm 3$ & 1.10 \\
Mg 1.98 TiN & $130 \pm 7$ & $103 \pm 5$ & 1.26 \\
Mg 2.5 TiN & $135 \pm 8$ & $82 \pm 3$ & 1.64 \\
\hline
\end{tabular}

\section{Materials and Methods}

\subsection{Materials}

In the present study, > 99.9\% pure elemental magnesium turnings supplied by ACROS organics, New Jersey, USA, were used as the base material and the required amount of pure titanium nitride (TiN) powder of size $\sim 20 \mathrm{~nm}$ and purity $>99.2 \%$ supplied by US Research Nanomaterials, Inc. (Houston, TX, USA), was used as the reinforcement phase.

\subsection{Processing}

\subsubsection{Primary Processing}

Pure magnesium and $\mathrm{Mg}(0.58,0.97,1.98$, and 2.5$)$ vol. \% TiN nanocomposites were synthesized by a disintegrated melt deposition technique. Within a graphite crucible, pure magnesium turnings and TiN nanoparticulates (NPs) were placed in a multilayered sandwich fashion and superheated to $750{ }^{\circ} \mathrm{C}$ under an argon gas atmosphere using a resistance heating furnace. For uniform distribution of NPs within the metal matrix, the superheated slurry was stirred at $465 \mathrm{rpm}$ for 6 min using a twin-blade stirrer with a pitch of $45^{\circ}$. ZIRTEX 25 coating was applied on the stirrer to avoid iron contamination of the molten metal. After stirring, the molten metal was then poured into the mold, under the influence of gravity, through a $10 \mathrm{~mm}$ hole in the crucible. Before entering the mold, the molten metal was disintegrated by two jets of argon gas oriented normal to the melt stream. The flow rate of argon was maintained at $25 \mathrm{lpm}$ and an ingot of $40 \mathrm{~mm}$ diameter was obtained. For synthesizing pure magnesium, no NPs were added and the above steps were followed. The $40 \mathrm{~mm}$ diameter ingots obtained were then machined to a diameter of $36 \mathrm{~mm}$ for hot extrusion.

\subsubsection{Secondary Processing}

Before extrusion, the machined ingots were soaked at $400^{\circ} \mathrm{C}$ for $1 \mathrm{~h}$ in a constant temperature furnace. Using a $150 \mathrm{~T}$ hydraulic press, hot extrusion was carried out at $350{ }^{\circ} \mathrm{C}$ die temperature, with an extrusion ratio of 20.25:1 for obtaining rods of $8 \mathrm{~mm}$ in diameter. The samples from the extruded rods were used for characterization, as detailed in the next section.

\subsection{Materials Characterization}

\subsubsection{Density Measurements}

Density of extruded pure $\mathrm{Mg}$ and $\mathrm{Mg}$-TiN nanocomposites in polished condition was measured using Archimedes principle. Three samples from different ends of the extruded rods were accurately weighed in air and then immersed in distilled water. An A and D ER-182A electronic balance with an accuracy of $0.0001 \mathrm{~g}$ was used for measuring the weights. Using the rule of mixtures principle, 
the theoretical densities of the synthesized Mg materials were calculated. Porosity values of the synthesized Mg materials were calculated utilizing Equation (6):

$$
\text { Porosity }=\frac{\rho_{t h}-\rho_{\text {exp }}}{\rho_{\text {th }}-\rho_{\text {air }}} \times 100
$$

where $\rho_{t h}$ is the theoretical density $\left(\mathrm{g} / \mathrm{cm}^{3}\right) ; \rho_{\text {exp }}$ is the experimental density in $\left(\mathrm{g} / \mathrm{cm}^{3}\right)$; and $\rho_{\text {air }}$ is the density of air $\left(0.001225 \mathrm{~g} / \mathrm{cm}^{3}\right)$.

\subsubsection{X-ray Diffraction Studies}

The extruded pure magnesium and $\mathrm{Mg}$-TiN nanocomposite samples were exposed to $\mathrm{Cu} \mathrm{K} \alpha$ radiation of wavelength $\lambda=1.54056 \AA$ with a scan speed of $2 \%$ min by using an automated Shimadzu lab-X XRD-6000 diffractometer (Shimadzu, Kyoto, Japan). The Bragg angles and the values of the interplanar spacing, $d$, obtained were subsequently matched with the standard values of $\mathrm{Mg}$, TiN and related phases. Further, the basal plane orientation of $\mathrm{Mg}$-TiN nanocomposites was analyzed based on the XRD peaks obtained from experiments carried out in the directions both parallel and perpendicular to the extrusion axis.

\subsubsection{Microstructural Characterization}

To investigate on TiN reinforcement distribution and grain size of pure magnesium and $\mathrm{Mg}$-TiN nanocomposites, the microstructural characterization studies were conducted on metallographically-polished extruded samples and a Hitachi S-4300 field emission scanning electron microscope (FESEM) (Hitachi, Tokyo, Japan), an Olympus metallographic optical microscope (Tokyo, Japan) and Scion image analysis software (Scion, Sacramento, CA, USA) were utilized. For every nanocomposite sample, five micrographs were utilized for more accurate estimation of grain size.

\subsubsection{Coefficient of Thermal Expansion (CTE)}

By using a thermo-mechanical analysis instrument "LINSEIS TMA PT 1000LT" (Linseis, Princeton Junction, NJ, USA), the coefficient of thermal expansion values of pure magnesium and Mg-TiN nanocomposites were determined. Heating rate of $5{ }^{\circ} \mathrm{C} / \mathrm{min}$ was maintained with an argon flow rate of $0.1 \mathrm{lpm}$. By using an alumina probe, the displacement of the test samples (each of $5 \mathrm{~mm}$ length) was measured as a function of temperature (323 to $623 \mathrm{~K}$ ).

\subsubsection{Microhardness Test}

Using a Shimadzu HMV automatic digital microhardness tester (Shimadzu, Kyoto, Japan) with a Vickers indenter (square based pyramidal shaped diamond indenter with a phase angle of $136^{\circ}$ ), the microhardness tests were conducted on flat and metallographically-polished specimens. An indenting load of $25 \mathrm{gf}$ for a dwell time of $15 \mathrm{~s}$ was used. The testing was performed as per ASTM E384-11e1.

\subsubsection{Tensile Test}

In accordance with ASTM E8/E8M-15a, the smooth bar tensile properties of pure magnesium and $\mathrm{Mg}$-TiN nanocomposites were determined at ambient temperature. The tensile tests were conducted on round tension test specimens of $5 \mathrm{~mm}$ diameter and gauge length $25 \mathrm{~mm}$ using a fully automated servo-hydraulic mechanical testing machine, MTS-810. The strain rate was set to $1.693 \times 10^{-4} \mathrm{~s}^{-1}$ and an Instron 2630-100 series extensometer (Instron, Singapore) was used to measure the fracture strain. For each composition, five samples were tested to ensure repeatable values.

\subsubsection{Compression Test}

In accordance with ASTM E9-09, the smooth bar compressive properties of the extruded pure magnesium and Mg-TiN samples were determined at ambient temperature, using a MTS-810 testing 
machine (Instron, Singapore) with a strain rate of $8.334 \times 10^{-5} \mathrm{~s}^{-1}$. The test specimens of $8 \mathrm{~mm}$ diameter and length to diameter ratio $1 / d \sim 1$ were used. For each composition, five samples were tested to ensure repeatable values.

\subsubsection{Fracture Behavior}

To provide an insight into the various possible fracture mechanisms operating during the tensile and compression loading of the samples, characterization of fractured surfaces of tensile and compression samples were successfully investigated using Hitachi S-4300 FESEM (Hitachi, Tokyo, Japan).

\section{Conclusions}

In the present study, $\mathrm{Mg}(0.58,0.97,1.98$, and 2.5$)$ vol. \% TiN nanocomposites are synthesized by a disintegrated melt deposition technique followed by hot extrusion. An attempt is made to study and compare the effect of type of Ti based (metal and ceramic) NPs, their size, and volume fraction addition on the microstructural and mechanical properties of pure $\mathrm{Mg}$.

The following are the primary conclusions of the present study:

(a) Utilizing the adopted synthesis methodology (disintegrated melt deposition technique followed by hot extrusion), near dense Mg-Ti based nanocomposites containing low-volume fraction $\mathrm{Ti}$ (metal) and ceramics of Ti NPs can be synthesized. It is observed that with a marginal increase in the density of pure $\mathrm{Mg}$, the presence of Ti-based NPs significantly improves its mechanical properties.

(b) Microstructural characterization indicate significant grain refinement of pure $\mathrm{Mg}$ with the addition of TiN NPs and Mg 2.5 vol. \% TiN exhibited a minimum grain size of $11 \mu \mathrm{m}$, which is $57 \%$ lower than that of pure $\mathrm{Mg}$. Among the Mg-Ti based nanocomposites, Mg $1.98 \mathrm{vol} . \% \mathrm{Ti}$ (metal) nanocomposites exhibited the lowest grain size of $\sim 1.5 \mu \mathrm{m}$.

(c) Microhardness values of pure Mg increases with the addition of TiN NPs and Mg 2.5 vol. \% TiN exhibited the maximum hardness value of $\sim 67 \mathrm{HV}$, which is $26 \%$ greater than that of pure $\mathrm{Mg}$. Among the Mg-Ti based nanocomposites, $\mathrm{Mg} 1.98$ vol. \% $\mathrm{TiB}_{2}$ exhibited the maximum hardness value of $\sim 76 \mathrm{HV}$.

(d) Room temperature tensile properties of Mg-TiN nanocomposites indicate an increase in the strength properties of pure $\mathrm{Mg}$ with addition of $\geqslant$ (greater than or equal to) $0.97 \mathrm{TiN}$ NPs. $\mathrm{Mg} 2.5$ vol. \% TiN nanocomposites exhibited the maximum $0.2 \%$ TYS and UTS of $135 \mathrm{MPa}$ and $\sim 196 \mathrm{MPa}$, respectively, which are $\sim 26 \%$ and $\sim 17 \%$ greater than that of pure $\mathrm{Mg}$.

(e) X-ray diffraction studies indicated that addition of up to $1.98 \mathrm{vol}$. \% TiN NPs has the ability to modify the basal texture of hot extruded pure $\mathrm{Mg}$. The tensile fracture strain values of pure $\mathrm{Mg}$ was found to increase with up to 1.98 vol. \% TiN NPs addition and $\mathrm{Mg}(0.58,0.97,1.98)$ vol. \% TiN exhibited the maximum tensile fracture strain values of $\sim 15 \%$. With further addition of TiN NPs (2.5 vol. \%), strong basal texture of pure $\mathrm{Mg}$ was observed and the tensile fracture strain values of $\mathrm{Mg} 2.5 \mathrm{vol}$. \% TiN was found to decrease to $\sim 10.5 \%$. Further, critical quantity of $\mathrm{Ti}$ (ceramic) NPs contribute to modifying the basal texture of pure $\mathrm{Mg}$ and thereby enhance the fracture strain values, whereas no textural changes of pure Mg reinforced with metallic Ti NPs was observed.

(f) Among the major strengthening mechanisms of Mg MMNCs containing Ti-based NPs, Hall-Petch strengthening contribution was found to play a vital role. $\mathrm{Mg}-\mathrm{Ti}$ (metal) nanocomposites exhibited the maximum $0.2 \%$ TYS with significant Hall-Petch contributions and Mg 1.98 vol. \% Ti possessed $0.2 \%$ TYS as high as $162 \mathrm{MPa}$. Among the Mg-Ti (ceramic) nanocomposites, $\mathrm{Mg} 1.98 \mathrm{TiB}_{2}$ exhibited $0.2 \%$ TYS as high as $\sim 140 \mathrm{MPa}$. 
(g) Room temperature compression properties of $\mathrm{Mg}$-TiN nanocomposites indicate that, with the addition of up to 1.98 vol. \% TiN the $0.2 \%$ CYS, UCS and compressive fracture strain values of pure $\mathrm{Mg}$ was found to increase. Mg $1.98 \mathrm{vol}$ \% TiN exhibited the highest $0.2 \mathrm{CYS}, \mathrm{UCS}$ and compressive fracture strain values of $\sim 103 \mathrm{MPa}, \sim 385 \mathrm{MPa}$, and $\sim 21 \%$, respectively, which are $\sim 28 \%, \sim 11 \%$, and $\sim 7 \%$ greater than that of pure Mg. With further addition of TiN (2.5 vol. \%) NPs, the compression strength properties were found to decrease with $0.2 \% \mathrm{CYS}$ and UCS of $\sim 82 \mathrm{MPa}$ and $\sim 342 \mathrm{MPa}$, respectively. Mg-Ti (ceramic) nanocomposites were found to exhibit higher compressive fracture strain, whereas strengthening was predominantly observed in $\mathrm{Mg}-\mathrm{Ti}$ (metal) nanocomposites.

(h) Further, addition of up to 1.98 vol. \% TiN NPs aids in minimizing the TCA value of pure Mg and $\mathrm{Mg}$ (0.58 and 0.97) TiN exhibited the minimum TCA value of $\sim 1.10$.

\section{Abbreviations}

The following abbreviations are used in this manuscript:

\begin{tabular}{|c|c|}
\hline$\sigma_{M g}$ & Tensile yield strength of monolithic pure $\mathrm{Mg}(\mathrm{MPa})$ \\
\hline$\sigma_{\text {Orowan }}$ & Orowan strengthening contribution $(\mathrm{MPa})$ \\
\hline$\sigma_{\text {Hall- }}$ Petch & Hall-Petch strengthenig contribution (MPa) \\
\hline$\sigma_{C T E}$ & Forest strengthening contribution (MPa) \\
\hline$\sigma_{E M}$ & Taylor strengthening contribution (MPa) \\
\hline$\sigma_{L T}$ & Strengthening due to load transfer (MPa) \\
\hline$\rho_{t h}$ & Theoretical density (g/cc) \\
\hline$\rho_{\text {exp }}$ & Experimental density (g/cc) \\
\hline $0.2 \% \mathrm{TYS}$ & 0.2\% Tensile Yield Strength (MPa) \\
\hline $0.2 \%$ CYS & $0.2 \%$ Compressive Yield Strength (MPa) \\
\hline CTE & Coefficient of thermal expansion $(\mu / \mathrm{K})$ \\
\hline$d_{p}$ & Average Diameter of the NPs (m) \\
\hline MMNCs & Metal Matrix Nanocomposites \\
\hline NPs & Nanoparticulates \\
\hline $\mathrm{r}$ & Average radius of NPs (m) \\
\hline TCA & Tensile Compression Asymmetry \\
\hline UCS & Ultimate Compression Strength (MPa) \\
\hline UTS & Ultimate Tensile Strength (MPa) \\
\hline XRD & X-Ray Diffraction \\
\hline$v_{p}$ & Volume fraction of NPs (\%) \\
\hline
\end{tabular}

Acknowledgments: One of the authors, Ganesh Kumar Meenashisundaram, sincerely thank National University of Singapore for the NUS Research Scholarship support towards his graduate studies. The authors also gratefully acknowledge Hong Wei, lab officer, Mechanical Engineering Department, National University of Singapore for his extended support towards measurement of CTE and ensuring availability of lab equipment for continuous research.

Author Contributions: All the authors contributed to the paper. Ganesh Kumar Meenashisundaram was involved in synthesis and characterization of Mg nanocomposites. Ganesh Kumar Meenashisundaram and Mui Hoon Hai provided the analysis in the paper and prepared the manuscript. Abdulhakim Almajid and Manoj Gupta designed the scope of the paper. All authors discussed the conclusions and reviewed the manuscript.

Conflicts of Interest: The authors declare no conflict of interest. 


\section{References}

1. Kirkland, N.; Birbilis, N.; Staiger, M. Assessing the corrosion of biodegradable magnesium implants: A critical review of current methodologies and their limitations. Acta Biomater. 2012, 8, 925-936. [CrossRef] [PubMed]

2. Goh, C.; Wei, J.; Lee, L.C.; Gupta, M. Development of novel carbon nanotube reinforced magnesium nanocomposites using the powder metallurgy technique. Nanotechnology 2006, 17. [CrossRef]

3. Itoi, T.; Takahashi, K.; Moriyama, H.; Hirohashi, M. A high-strength Mg-Ni-Y alloy sheet with a long-period ordered phase prepared by hot-rolling. Scr. Mater. 2008, 59, 1155-1158. [CrossRef]

4. Nguyen, Q.; Gupta, M.; Srivatsan, T. On the role of nano-alumina particulate reinforcements in enhancing the oxidation resistance of magnesium alloy AZ31B. Mater. Sci. Eng. A 2009, 500, 233-237. [CrossRef]

5. Shaw, B.; Wolfe, R. Corrosion of magnesium and magnesium-base alloys. ASM Handb. Corros. Mater. 2005, 13, 205-227.

6. Cramer, S.D.; Covino, B.S., Jr.; Moosbrugger, C.; ASM International Handbook Committee. ASM Handbook; Asm International: Materials Park, OH, USA, 2005; Volume 13.

7. Gupta, M.; Meenashisundaram, G.K. Insight Into Designing Biocompatible Magnesium Alloys and Composites: Processing, Mechanical and Corrosion Characteristics; Springer: Singapore, Singapore, 2015.

8. Farraro, K.F.; Kim, K.E.; Woo, S.L.; Flowers, J.R.; McCullough, M.B. Revolutionizing orthopaedic biomaterials: The potential of biodegradable and bioresorbable magnesium-based materials for functional tissue engineering. J. Biomech. 2014, 47, 1979-1986. [CrossRef] [PubMed]

9. Staiger, M.P.; Pietak, A.M.; Huadmai, J.; Dias, G. Magnesium and its alloys as orthopedic biomaterials: A review. Biomaterials 2006, 27, 1728-1734. [CrossRef] [PubMed]

10. Zreiqat, H.; Howlett, C.; Zannettino, A.; Evans, P.; Schulze-Tanzil, G.; Knabe, C.; Shakibaei, M. Mechanisms of magnesium-stimulated adhesion of osteoblastic cells to commonly used orthopaedic implants. J. Biomed. Mater. Res. 2002, 62, 175-184. [CrossRef] [PubMed]

11. Manivasagam, G.; Dhinasekaran, D.; Rajamanickam, A. Biomedical implants: Corrosion and its prevention-a review. Recent Pat. Corros. Sci. 2010, 2, 40-54. [CrossRef]

12. Xin, Y.; Hu, T.; Chu, P.K. In vitro studies of biomedical magnesium alloys in a simulated physiological environment: A review. Acta Biomater. 2011, 7, 1452-1459. [CrossRef] [PubMed]

13. Esen, Z.; Dikici, B.; Duygulu, O.; Dericioglu, A.F. Titanium-magnesium based composites: Mechanical properties and in vitro corrosion response in Ringer's solution. Mater. Sci. Eng. A 2013, 573, 119-126. [CrossRef]

14. Habibi, M.K.; Joshi, S.P.; Gupta, M. Hierarchical magnesium nano-composites for enhanced mechanical response. Acta Mater. 2010, 58, 6104-6114. [CrossRef]

15. Meenashisundaram, G.K.; Gupta, M. Low volume fraction nano-titanium particulates for improving the mechanical response of pure magnesium. J. Alloys Compd. 2014, 593, 176-183. [CrossRef]

16. Buhagiar, J.; Dong, H. Corrosion properties of S-phase layers formed on medical grade austenitic stainless steel. J. Mater. Sci. Mater. Med. 2012, 23, 271-281. [CrossRef] [PubMed]

17. Ivanova, E.P.; Bazaka, K.; Crawford, R.J. New Functional Biomaterials for Medicine and Healthcare; Woodhead Publishing: Cambridge, UK, 2014.

18. Meenashisundaram, G.K.; Sankaranarayanan, S.; Gupta, M. Enhancing overall tensile and compressive response of pure Mg using nano-TiB2 particulates. Mater. Charact. 2014, 94, 178-188. [CrossRef]

19. Arsiwala, A.; Desai, P.; Patravale, V. Recent advances in micro/nanoscale biomedical implants. J. Controll. Release 2014, 189, 25-45. [CrossRef] [PubMed]

20. Reed-Hill, R.E.; Abbaschian, R. Physical Metallurgy Principles; Cengage Learning: Stamford, CA, USA, 1973.

21. Tun, K.; Jayaramanavar, P.; Nguyen, Q.; Chan, J.; Kwok, R.; Gupta, M. Investigation into tensile and compressive responses of Mg-ZnO composites. Mater. Sci. Technol. 2012, 28, 582-588. [CrossRef]

22. Wang, H.; Jiang, Q.; Wang, Y.; Ma, B.; Zhao, F. Fabrication of $\mathrm{TiB}_{2}$ particulate reinforced magnesium matrix composites by powder metallurgy. Mater. Lett. 2004, 58, 3509-3513. [CrossRef]

23. Chawla, N.; Jones, J.; Andres, C.; Allison, J. Effect of SiC volume fraction and particle size on the fatigue resistance of a $2080 \mathrm{Al} / \mathrm{SiC}$ p composite. Metall. Mater. Trans. A 1998, 29, 2843-2854. [CrossRef]

24. Smithells, C. Smithells Metal Reference Book, 7th ed.; Butterworth-Heinemann: Boston, MA, USA, 1992.

25. Milman, V.; Warren, M. Elastic properties of $\mathrm{TiB}_{2}$ and $\mathrm{MgB}_{2}$. J. Phys. Condens. Matter 2001, $13,5585$. [CrossRef] 
26. Emamy, M.; Mahta, M.; Rasizadeh, J. Formation of $\mathrm{TiB}_{2}$ particles during dissolution of $\mathrm{TiAl}_{3}$ in $\mathrm{Al}-\mathrm{TiB}_{2}$ metal matrix composite using an in situ technique. Compos. Sci. Technol. 2006, 66, 1063-1066. [CrossRef]

27. Tao, X.; Du, J.; Yang, Y.; Li, Y.; Xia, Y.; Gan, Y.; Huang, H.; Zhang, W.; Li, X. TiC nanorods derived from cotton fibers: Chloride-assisted VLS growth, structure, and mechanical properties. Cryst. Growth Des. 2011, 11, 4422-4426. [CrossRef]

28. Shackelford, J.F.; Alexander, W. CRC Materials Science and Engineering Handbook; CRC Press: Boca Raton, FL, USA, 2000.

29. Ferguson, J.; Sheykh-Jaberi, F.; Kim, C.-S.; Rohatgi, P.K.; Cho, K. On the strength and strain to failure in particle-reinforced magnesium metal-matrix nanocomposites (Mg MMNCs). Mater. Sci. Eng. A 2012, 558, 193-204. [CrossRef]

30. Dieter, G.E.; Bacon, D. Mechanical Metallurgy; McGraw-Hill: New York, NY, USA, 1986; Volume 119.

31. Gale, W.F.; Totemeier, T.C. Smithells Metals Reference Book; Butterworth-Heinemann: Boston, MA, USA, 2003.

32. Han, B.; Dunand, D. Microstructure and mechanical properties of magnesium containing high volume fractions of yttria dispersoids. Mater. Sci. Eng. A 2000, 277, 297-304. [CrossRef]

33. Zhang, Q.; Chen, D. A model for predicting the particle size dependence of the low cycle fatigue life in discontinuously reinforced MMCs. Scripta Mater. 2004, 51, 863-867. [CrossRef]

34. Meyers, M.A.; Chawla, K.K. Mechanical Behavior of Materials; Cambridge University Press: Cambridge, UK, 2009; Volume 2.

35. Goh, C.; Wei, J.; Lee, L.; Gupta, M. Properties and deformation behaviour of $\mathrm{Mg}-\mathrm{Y}_{2} \mathrm{O}_{3}$ nanocomposites. Acta Mater. 2007, 55, 5115-5121. [CrossRef]

36. Vogt, R.; Zhang, Z.; Li, Y.; Bonds, M.; Browning, N.; Lavernia, E.; Schoenung, J. The absence of thermal expansion mismatch strengthening in nanostructured metal-matrix composites. Scripta Mater. 2009, 61, 1052-1055. [CrossRef]

37. Chawla, N.; Habel, U.; Shen, Y.-L.; Andres, C.; Jones, J.; Allison, J. The effect of matrix microstructure on the tensile and fatigue behavior of $\mathrm{SiC}$ particle-reinforced $2080 \mathrm{Al}$ matrix composites. Metall. Mater. Trans. A 2000, 31, 531-540. [CrossRef]

38. Meenashisundaram, G.K.; Nai, M.H.; Gupta, M. Effects of primary processing techniques and significance of hall-petch strengthening on the mechanical response of magnesium matrix composites containing $\mathrm{TiO}_{2}$ nanoparticulates. Nanomaterials 2015, 5, 1256-1283. [CrossRef]

39. Watanabe, H.; Ishikawa, K. Effect of texture on high temperature deformation behavior at high strain rates in a Mg-3Al-1Zn alloy. Mater. Sci. Eng. A 2009, 523, 304-311. [CrossRef]

40. Ulacia, I.; Dudamell, N.; Gálvez, F.; Yi, S.; Pérez-Prado, M.; Hurtado, I. Mechanical behavior and microstructural evolution of a Mg AZ31 sheet at dynamic strain rates. Acta Mater. 2010, 58, 2988-2998. [CrossRef]

(C) 2016 by the authors; licensee MDPI, Basel, Switzerland. This article is an open access article distributed under the terms and conditions of the Creative Commons by Attribution (CC-BY) license (http://creativecommons.org/licenses/by/4.0/). 